\title{
Eschatologie und Kommunikation im 6. Jahrhundert n. Chr. - oder: Wie Osten und Westen beständig aneinander vorbei redeten
}

\author{
Mischa Meier
}

I.

Der fortschreitende Prozeß der europäischen Einigung hat in den letzten Jahren auch in den Geschichtswissenschaften ein wachsendes Interesse gefunden. Nicht nur in den Teildisziplinen der Neueren und Neuesten Geschichte, sondern auch im Hinblick auf die Vormoderne geraten zunehmend Fragestellungen in den Fokus der Forschung, die auf die Ursprünge des modernen Europa ausgerichtet sind. Mit Blick auf die Antike wäre etwa auf die Konzeption des Neuen Pauly zu verweisen, des gerade vollendeten aktuellen Standardlexikons zur Antike und ihrer Nachwirkung. ${ }^{1}$ Erst vor kurzem hat darüber hinaus WolfGANG SCHUlLER im neuen Handbuch der Geschichte Europas als ersten Band eine Einführung in die Alte Geschichte unter dem Titel Das Erste Europa 1000 v. Chr.-500 n. Chr. vorgelegt ${ }^{2}$ in der Rezeptions- und Wissenschaftsgeschichte kommt dem Thema ,Europa und die Antike' mittlerweile ebenfalls eine zentrale Bedeutung zu, ${ }^{3}$ und eine größere Anzahl weiterer Projekte, in denen die Antike aus einer ,europäischen' Perspektive untersucht wird, befindet sich in Vorbereitung.

Innerhalb dieser aktuellen Debatten nehmen die Spätantike und das Frühmittelalter eine besondere Stellung ein. Denn das halbe Jahrtausend zwischen Konstantin und Karl d. Gr., d.h. der Zeitraum von der allmählichen Auflösung des Imperium Romanum bis hin zur Ausbildung der frühmittelal-

1 H. Cancik/H. Schneider/M. Landfester (Hgg.), Der Neue Pauly. Enzyklopädie der Antike, 19 Bde. Stuttgart/Weimar 1996-2003.

2 W. Schuller, Das Erste Europa 1000 v. Chr.-500 n.Chr. (Handbuch der Geschichte Europas, 1). Stuttgart 2004.

3 Vgl. etwa H. Hofmann (Hg.), Antike Mythen in der europäischen Tradition. Tübingen 1999; G. Lohse, Aktualisierung von Antike und Epochenbewußtsein. Erstes Bruno Snell-Symposion der Universität Hamburg am Europa-Kolleg. Leipzig 2003. Auf dem 44. Deutschen Historikertag in Halle/Saale 2002 widmete sich die Sektion „Europa in der Antike - Traditionen oder retrospektive Vision?" dem Themenbereich, vgl. dazu die Kurzzusammenfassungen der Vorträge in: A. Ranft/M. Meumann (Hgg.), Traditionen Visionen. 44. Deutscher Historikertag in Halle an der Saale vom 10. bis 13. September 2002. Berichtsband, München 2003, 39-43. 
terlichen Mächtekonstellation, gilt gemeinhin als Formierungsphase des modernen Europa. $\mathrm{Zu}$ diesem Themenkomplex sind in den letzten Jahren verschiedene größere Arbeiten erschienen. Eine besonders prominente Stellung nimmt darunter das 1997 begonnene Großprojekt The Transformation of the Roman World ein (inzwischen abgeschlossen), aus dem 14 Bände hervorgegangen sind, die große Beachtung gefunden haben. Aber auch in anderen Untersuchungen wurde in den letzten Jahren versucht, diese Übergangsphase aus der europäischen Perspektive zu beleuchten. ${ }^{4} \mathrm{Zu}$ den zentralen Publikationen in diesem Kontext wird man Michael McCormicks monumentale Studie über Kommunikation, Migration, Handel und Gewerbe im europäischen Raum zwischen 300 und 900 n. Chr. rechnen dürfen. ${ }^{5}$ Der Autor versucht in diesem Buch einmal mehr, die berühmte und vieldiskutierte These Henri Pirennes zu widerlegen, wonach die sich etablierenden islamischen Zentren den ohnehin nur noch spärlichen Austausch zwischen Mittel- bzw. Zentraleuropa einerseits und dem mediterranen Raum andererseits gänzlich abgeschnitten hätten. ${ }^{6}$ MCCoRMICK versucht dagegen zu zeigen, daß gerade die islamische Expansion nachhaltigen Einfluß auf die Ausbildung neuer Kommunikationsstrukturen und Handelswege in Europa vor allem seit dem späten 8. Jahrhundert ausgeübt hat. Innerhalb seiner Argumentation, die sich hauptsächlich auf die Phase 700-900 konzentriert, werden auch Aspekte der Kommunikation zwischen dem ehemaligen Westteil des Römischen Reiches und den oströmisch-byzantinischen Regionen in der ausgehenden Spätantike behandelt, und damit wird implizit ein Fragenkomplex mitaufgegriffen, um den es auch mir im folgenden gehen soll, nämlich das Problem der Entstehung des späteren Europa aus dem ehemaligen Imperium Romanum heraus bei gleichzeitiger Aufgabe der gesamten Osthälfte dieses Reiches, obwohl - oder vielleicht gerade weil - diese anders als der Westteil in wesentlich deutlicherer Kontinuität zum antiken Römischen Reich fortexistiert hat.

4 Vgl. etwa P. Brown, Die Entstehung des christlichen Europa. München 1996; L. Webster/M. Brown (Hgg.), The Transformation of the Roman World AD 400-900. Berkeley/Los Angeles 1997; F. Prinz, Von Konstantin zu Karl dem Großen. Entfaltung und Wandel Europas. Düsseldorf/Zürich 2000; J. Le Goff, Die Geburt Europas im Mittelalter. München ${ }^{3} 2004$, 29-47; V. Postel, Die Ursprünge Europas. Migration und Integration im frühen Mittelalter. Stuttgart 2004. Vollkommen mißglückt ist dagegen der universalgeschichtliche, in der Reihe „Europa im Mittelalter" erschienene Versuch von E. Pitz, Die griechisch-römische Ökumene und die drei Kulturen des Mittelalters. Geschichte des mediterranen Weltteils zwischen Atlantik und Indischem Ozean 270812 (Europa im Mittelalter, 3). Berlin 2001 (vgl. dazu meine Besprechung in: Das Altertum 47 [2002] 262-265).

5 M. McCormick, Origins of the European Economy. Communications and Commerce AD 300-900. Cambridge 2001 (ND 2002).

6 Vgl. H. Pirenne, Mahomet et Charlemagne. Paris/Brüssel 1937. 
McCormick zeichnet für die Spätantike - in weitgehender Übereinstimmung mit der älteren Forschung - das Bild eines allmählichen Niedergangs, der im Westen etwas früher als im Osten eingesetzt habe. Dieser Niedergang sei aber keinesfalls als flächendeckendes Phänomen anzusehen, das überall ähnlich lange angedauert habe, sondern als komplexer Prozeß, bei dem in erheblichem Maße regional und zeitlich zu differenzieren sei. Abgebrochen sei die Kommunikation zwischen Ost und West jedenfalls keineswegs. Vielmehr müsse man geradezu vom Gegenteil ausgehen: Schriftliche und materielle Zeugnisse ließen auf einen weiterhin vorhandenen, wenn auch nicht mehr ganz so regen Austausch schließen. Gesandte und Pilger, aber auch Flüchtlinge, Exulanten, Immigranten, Sklaven und Händler und ihre jeweiligen, nur umrißhaft erkennbaren Begleiter seien weiterhin permanent unterwegs gewesen, Reliquientranslationen und Münzumläufe deuteten zudem auf weitreichende Beziehungen und Verflechtungen zwischen den Regionen des ehemaligen Römischen Reiches - und darüber hinaus. Trotz des generell in spätrömischer Zeit zu verzeichnenden Rückgangs solcher Kontakte sei - so die zentrale These MсCовміскs - auch vor dem von ihm nachgewiesenen allgemeinen Aufschwung gegen Ende des 8 . Jahrhunderts die Kommunikation selbst über größere Distanzen hinweg weiterhin aufrecht erhalten worden.

Europa - verstanden als kulturelles Konstrukt, wie man es häufig insbesondere in der durch das Imperium Romanum geschaffenen und über Jahrhunderte hinweg bewahrten Koine fassen zu können glaubt - wäre demzufolge nicht in der Übergangsphase nach dem Ende des Weströmischen Reiches zunächst auseinandergefallen, um dann vor allem seit karolingischer Zeit zu neuer Einheit zu finden, sondern hätte auch die wechselvollen, turbulenten Jahre seit etwa 500 n. Chr. zumindest in elementarer Form überdauert. Denn die Kommunikation zwischen den weit auseinanderliegenden ehemaligen Territorien des Reiches sei ja immerhin nicht abgebrochen, und - so die von IAN WooD auf den Punkt gebrachte allgemeine Ansicht - „communication is, indeed, at the heart of the question of the transformation of the Roman world". MCCormick plädiert mithin für eine kontinuierliche Entwicklung vom spätrömischen Imperium Romanum zur mittelalterlichen Mächtekonstellation als Präfiguration des modernen Europa, und seine Thesen sind in den letzten Jahren auf ausgesprochen positive Resonanz gestoßen.

Trotzdem halte ich diesen Ansatz für problematisch. Denn er setzt ein ausgesprochen mechanistisch ausgerichtetes Konzept von Kommunikation voraus, ein Konzept, das bereits dann als erfüllt angesehen wird, wenn der Nachweis erbracht wurde, daß gereist wurde, daß gehandelt und verhandelt

7 I. Wood, Modes of Communication: An Afterword, in: E. Chrysos/I. Wood (Hgg.), East and West: Modes of Communication. Proceedings of the First Plenary Conference at Merida (TRW 5). Leiden/Boston/Köln 1999, 279-282, hier 279. 
wurde oder daß Münzen und Waren weite Entfernungen zurücklegen konnten. Aber worüber redete eigentlich der byzantinische Händler mit seinem fränkischen Kunden, wenn das Geschäft im engeren Sinne abgeschlossen war? Was hatte der Bischof einer merowingischen Siedlung einem Gesandten aus Konstantinopel zu erzählen? Hatte man denn überhaupt gemeinsame Themen, die für beide Seiten von Interesse waren? Gab es Ebenen des Austausches, die jenseits der unmittelbaren politischen oder ökonomischen Aspekte anzusiedeln sind, und - wenn dies so ist - wie lassen sie sich fassen und beschreiben?

Ohne die Verdienste McCormicks und anderer schmälern zu wollen, muß man wohl doch die Frage stellen, ob die reichhaltigen Zeugnisse, die mittlerweile zu den Beziehungen zwischen West und Ost in der ausgehenden Spätantike gesammelt worden sind, wirklich als Indizien für Kommunikation in einem umfassenden Sinne verstanden werden können - oder ob sie nicht doch zunächst einmal nur Kontakte widerspiegeln, und mehr eben nicht. ${ }^{8}$

Die Behandlung der Frage nach Kommunikation zwischen dem lateinischsprachigen Westen und dem griechischen Osten ist methodisch heikel, denn das zur Verfügung stehende Quellenmaterial ist spärlich und disparat, und aus eben diesem Grunde scheinen bisher auch noch nicht allzu viele Untersuchungen zu diesem Problem vorzuliegen. ${ }^{9}$ Danach zu fragen, worüber Personen aus unterschiedlichen Regionen miteinander redeten und ob sie sich dabei verstanden, kann nämlich nicht darauf reduziert werden zu untersuchen, in welcher Sprache solche Zusammenkünfte möglicherweise stattgefunden haben

8 Der Nachweis bloßer Kontakte und wechselseitigen Austausches entspricht jedenfalls nicht modernen Theorien von Kommunikation und Kommunikationsprozessen; zu einer solchen siehe etwa N. Luhmann, Soziale Systeme. Grundriß einer allgemeinen Theorie. Frankfurt a. M. 1984 (ND Darmstadt 2002), 66 f.; 126 f.; $191 \mathrm{ff}$; $498 \mathrm{ff}$.

9 Vgl. etwa Av. Cameron, The Byzantine Sources of Gregory of Tours, JThS 26 (1975) 421-426; D. Claude, Der Handel im westlichen Mittelmeer während des Frühmittelalters (Untersuchungen zu Handel und Verkehr der vor- und frühgeschichtlichen Zeit in Mittel- und Nordeuropa, 2; Abhandlungen der Akademie der Wissenschaften in Göttingen, phil.-hist. Kl. 3,144). Göttingen 1985. Die politischen Kontakte zwischen Konstantinopel und den Merowingern im 6. und frühen 7. Jh. behandeln W. Goffart, Byzantine Policy in the West under Tiberius II and Maurice: The Pretenders Hermenegild and Gundovald (579-585), Traditio 13 (1957) 73-118, und E. Ewig, Die Merowinger und das Imperium (Rheinisch-Westfälische Akademie der Wissenschaften. Vorträge. G 261). Opladen 1983. Siehe auch B.S. Bachrach, The Anatomy of a Little War. A Diplomatic and Military History of the Gundovald Affair (568-586). Boulder/ San Francisco/Oxford 1994. Eine eng am Material gearbeitete Behandlung der byzantinischen Kontakte zu den Franken, nach Italien und Afrika seit dem späten 6. Jh. bietet P. Goubert, Byzance avant l'Islam, II/1-2: Byzance et l'Occident sous les successeurs de Justinien. Paris 1955/1965. Den Versuch einer systematischen Untersuchung des spätrömischen Gesandtenwesens bis in das 6. Jh. unternimmt R. Helm, Untersuchungen über den auswärtigen diplomatischen Verkehr des römischen Reiches im Zeitalter der Spätantike, Archiv für Urkundenforschung 12 (1932) 375-436. 
(hier geht es vor allem um die Alternative Latein oder Griechisch), wenngleich bereits das Sprachproblem in den jeweils konkreten Situationen des öfteren eine wichtige Rolle gespielt haben wird.

M.E. kann daher eine Methode, die weiterführende Ergebnisse verspricht, nur in folgender Vorgehensweise bestehen: Zunächst muß nach Themenfeldern gesucht werden, die im Untersuchungszeitraum sowohl für Personen aus dem Westen als auch für Menschen aus dem Osten von besonderer Relevanz gewesen sein müssen. Diese Themenbereiche dürfen nicht in Form eines Zirkelschlusses aus dem vorliegenden Material (das es dann später ja noch auszuwerten gilt) abgeleitet werden, sondern müssen mit Blick auf die allgemeinen Rahmenbedingungen in der ausgehenden Spätantike vorab erschlossen und festgelegt werden. In einem zweiten Schritt ist dann vergleichend zu untersuchen, wie der Diskurs über diese Themen - soweit überhaupt greifbar - in den beiden Hälften des ehemaligen Römischen Reiches jeweils ausgesehen hat, und schließlich ist sofern vorhanden - Quellenmaterial zu analysieren, in dem Personen aus dem Osten und aus dem Westen direkt über diese Themen miteinander in Verbindung treten.

Eine solche Untersuchung müßte, wollte man sie erschöpfend durchführen, das gesamte uns zur Verfügung stehende Quellenmaterial im Hinblick auf entsprechende Beispiele durcharbeiten und analysieren. Das kann in einem Aufriß, wie er hier vorliegt, nicht geleistet werden. Wohl aber ist es in diesem Rahmen möglich, für einen fest definierten Zeitabschnitt exemplarisch ein zentrales Themenfeld herauszugreifen und auf die skizzierte Fragestellung hin zu untersuchen. Für mich war es dabei u.a. aufgrund diverser Vorarbeiten naheliegend, mich zunächst auf die Endzeiterwartungen im 6. Jahrhundert zu konzentrieren. Denn eschatologische Spekulationen und Naherwartungen gehören seit dem irdischen Wirken Jesu zu den zentralen Elementen christlichen Denkens, ${ }^{10}$ und für das 6. Jahrhundert können weitestgehend christianisierte Gesellschaften in Ost und West vorausgesetzt werden, die insofern von diesem Denken geprägt sein mußten. Bereits ein flüchtiger Blick auf das entsprechende Quellenmaterial bestätigt das und zeigt überdies, daß es in diesem Zeitraum sowohl im Westen als auch im Osten zu einer Aktualisierung solcher Erwartungen bis hin zur Diskussion ganz konkreter, unmittelbar erwarteter Endzeitszenarien gekommen ist. Eschatologische Spekulationen und konkrete Endzeiterwartungen scheinen also eines der Themen gewesen zu sein, auf deren

10 Die Literatur zu diesem Thema ist reichhaltig. Ich verweise exemplarisch auf A. Kehl/H.I. Marrou, RAC 10 (1978) 703-779 (s.v. Geschichtsphilosophie); G. Klein, TRE 10 (1982) 270-299 (s.v. Eschatologie IV); K. Berger, Theologiegeschichte des Urchristentums. Tübingen/Basel ${ }^{2} 1995$, 34 ff.; R. Mortley, TRE 12 (1984) 604-608 (s.v. Geschichte, Geschichtsschreibung, Geschichtsphilosophie V). 
Basis Westen und Osten miteinander kommunizieren konnten - oder etwa doch nicht?

II.

Werfen wir zunächst einen Blick auf den Osten. Dort scheinen in den Jahren um 500 ganz konkrete, auf ein unmittelbar bevorstehendes Weltende hin ausgerichtete Ängste aufgekommen zu sein, die uns in zahlreichen Zeugnissen überliefert sind, ${ }^{11}$ in Zeugnissen, die im übrigen auch belegen, daß es sich bei diesen Erwartungen nicht nur um gesellschaftliche Randphänomene gehandelt hat, die nur in esoterischen Zirkeln diskutiert wurden, sondern daß tatsächlich wohl große Teile der damaligen oströmischen Bevölkerung vom Endzeitfieber ergriffen waren. ${ }^{12}$ Dafür, daß diese Aktualisierung von Naherwartungen ausgerechnet um das Jahr 500 erfolgte, lassen sich m. E. klare Gründe benennen: Als den Christen spätestens bis zum 3. Jahrhundert zunehmend bewußt wurde, daß das in den Evangelien verheißene und auch von Paulus als unmittelbar bevorstehend verkündete Weltende ${ }^{13}$ weiterhin auf sich warten ließ (Parusie-

11 Das Phänomen findet erst seit verhältnismäßig kurzer Zeit allmählich die ihm zukommende Aufmerksamkeit in der Forschung, vgl. P. Magdalino, The History of the Future and Its Uses: Prophecy, Policy and Propaganda, in: R. Beaton/Ch. Roueché (Hgg.), The Making of Byzantine History. Studies Dedicated to Donald M. Nicol. Aldershot 1993,

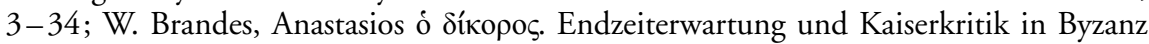
um 500 n. Chr., BZ 90 (1997) 24-63; A. Külzer, Konstantinopel in der apokalyptischen Literatur der Byzantiner, JÖB 50 (2000) 51-76; M. Meier, Das andere Zeitalter Justinians. Kontingenzerfahrung und Kontingenzbewältigung im 6. Jahrhundert n. Chr. (Hypomnemata 147). Göttingen ${ }^{2} 2004$.

12 So etwa die Chronik des Josua Stylites, vgl. bes. Jos. Styl. cap. 49 (Die syrische Chronik des Josua Stylites, übers. von A. Luther. Berlin/New York 1997, p. 65); dazu Brandes, Anastasios (wie Anm. 11), 40; Meier, Zeitalter (wie Anm. 11), 74 f.; ferner das Kontakion des Romanos Melodos Auf die Parusie Christi und den jüngsten Tag (Rom. Mel. 34, in: Sancti Romani Melodi Cantica. Cantica Genuina, ed. by P. Maas/C. A. Trypanis. Oxford 1963 [ND 1997], 266-275 = Rom. Mel. 50, in: Romanos le Mélode. Hymns, V. Introduction, texte critique, traduction et notes par J. Grosdidier de Matons [SC 283]. Paris 1981, 234-266); s. auch die Kontakien Auf die zehn Jungfrauen $I$ (Rom. Mel. 48 Maas/Trypanis 409-420 = 51 Grosdider de Matons 269-326) und Auf Erdbeben und Feuerbrand (Rom. Mel. 54 Maas/Trypanis 462-471 = 54 Grosdider de Matons 470-498); dazu Brandes, Anastasios, 41 ff.; Meier, Zeitalter, 78-84; Brandes, a.a.O., spricht nicht ganz zu unrecht von einer „Mentalität breitester Kreise der Gesellschaft" (28; ähnlich ebd. 43).

13 Mt 24,32-44; Mk 13,28-32; Lk 21,25-28; 1 Thess 4-5; 1 Kor 7,29-31; Röm 13,11. Dazu A. Vögtle, Röm 13,11-14 und die „Nah“-Erwartung, in: J. Friedrich/W. Pöhlmann/P. Stuhlmacher (Hgg.), Rechtfertigung. Festschrift E. Käsemann zum 70. Geburtstag. Tübingen/Göttingen 1976, 557-573. 
verzögerung), ${ }^{14}$ und als gleichzeitig im Rahmen der sog. Reichskrise gerade die Bedrückungen für die Christen durch eine allgemeine Verschlechterung der Lebensbedingungen und durch Christenverfolgungen zunahmen - was wiederum als Vorzeichen des nahenden Endes gedeutet werden konnte,$-{ }^{15}$ ergab sich zunehmend die Notwendigkeit, den eigenen Standpunkt in einer auf ein fest definiertes Eschaton hin ausgerichteten Weltgeschichte zu bestimmen. Im Rückgriff auf Ps 90 (89), 4 (vgl. auch 2 Petr 3,8) wurde der Schöpfungsbericht Gen 1,1-2,3 als typologische Vorwegnahme einer Weltwoche gedeutet, wobei man davon ausging, daß jedem Schöpfungstag ein Jahrtausend der Weltzeit entspräche. Zu Beginn des 7. Jahrtausends sollten dann die Parusie und das Weltende bzw. - nach der häufig anzutreffenden chiliastischen Interpretation eine 1000jährige Gottesherrschaft erfolgen. ${ }^{16}$ Eine Reihe von Gelehrten nahm nun die eigentlich entscheidende Frage in Angriff: Die Berechnung des aktuellen Standorts der Menschen innerhalb dieses 6000jährigen Kontinuums der Weltzeit. Nachdem Theophilos von Antiocheia bereits gegen Ende des 2. Jahrhunderts eine erste Kalkulation erstellt hatte, die vor allem noch im Kontext der chronologischen Absicherung des Altersbeweises der christlichen Wahrheit gegenüber konkurrierenden Modellen zu sehen ist, ${ }^{17}$ widmeten sich in der 1 . Hälfte des 3. Jahrhunderts der Chronograph Iulius Africanus und der römische Presbyter Hippolytos der Aufgabe, den aktuellen Standort der Menschheit zu errechnen. Ihr Ziel bestand darin zu beweisen, daß das Weltende noch nicht unmittelbar bevorstehe, daß entsprechende Ängste also unbegründet seien.

14 Zum Problem der Parusieverzögerung siehe etwa J. Timmermann, Nachapostolisches Parousiedenken. München 1968.

15 Zur Frage nach dem Umgang mit den sog. Krisenphänomenen im 3. Jh. unter den Christen siehe K. Strobel, Das Imperium Romanum im ,3. Jahrhundert'. Modell einer historischen Krise? (Historia Einzelschriften, 75). Stuttgart 1993, bes. 74 ff.; zur ,Reichskrise‘ vgl. Chr. Witschel, Krise - Rezession - Stagnation? Der Westen des römischen Reiches im 3. Jahrhundert n. Chr. (Frankfurter althistorische Untersuchungen, 4). Frankfurt a. M. 1999.

16 Vgl. B. Kötting, Endzeitprognosen zwischen Lactantius und Augustinus, HJb 77 (1957) $125-139$, bes. 126 ff.; K.-H. Schwarte, Die Vorgeschichte der augustinischen Weltalterlehre (Antiquitas, R. 1: Abhandlungen zur alten Geschichte, 12). Bonn 1966, 78 ff. Die heute bekannteste chiliastische Auslegung des Weltwochenschemas findet sich in der Offenbarung des Johannes (Apk 20); die wichtigsten Belege für chiliastisches Denken in der Antike bietet A. Wikenhauser, Die Herkunft der Idee des tausendjährigen Reiches in der Johannes-Apokalypse, RQ 45 (1937) 1-24; ders., Weltwoche und tausendjähriges Reich, ThQ 127 (1947) 399-417.

17 Theoph. Ant. ad Autol. 3,28 (M. Marcovich [Ed.], Theophilii Antiocheni ad Autolycum [Patristische Texte und Studien, 44]. Berlin/New York 1995, 134); dazu Schwarte, Vorgeschichte (wie Anm. 16), 120 f. mit Anm. 6; Strobel, Imperium Romanum (wie Anm. 15), 116. 
Beide Autoren setzten die Geburt Christi um das Weltjahr 5500 (Africanus) $^{18}$ bzw. 5502 (Hippolytos) an. ${ }^{19}$ Daraus ergab sich, daß das im Weltjahr $6000 \mathrm{zu}$ erwartende Weltende etwa 500 Jahre nach der Geburt Christi, d. h. um das Jahr 500 unserer christlichen Zeitrechnung anzusetzen war. Seitdem waren die Jahre um 500 eschatologisch vorbelastet. Denn die Kalkulationen des Africanus und des Hippolytos setzten sich trotz wiederholt geäußerter Kritik (vor allem durch Eusebios von Kaisareia, dazu s.u.) letztlich durch - zumindest im Osten. So datierte etwa die sog. proto-byzantinische Ära das Weltende in das Jahr 491, und die alexandrinischen Mönche Panodoros und Annianos errechneten im frühen 5. Jahrhundert die Jahre 507 bzw. 508. ${ }^{20}$

Und tatsächlich gibt es ernstzunehmende Indizien, die darauf hinweisen, daß die zunehmenden Endzeiterwartungen im Oströmischen Reich um 500 vor allem als eine Folge dieser chronologischen Spekulationen anzusehen sind, die dann eine zusätzliche Bestätigung und zugleich auch Dynamik dadurch erhielten, daß ausgerechnet um 500 eine Serie schwerster Naturkatastrophen und ungewöhnlicher Naturphänomene einsetzte und daß darüber hinaus der um 500 regierende Kaiser bezeichnenderweise den auf das griechische Wort anástasis

18 H. Gelzer, Sextus Julius Africanus und die byzantinische Chronographie, I. Leipzig 1880 bes. $24 \mathrm{ff}$; A.-D. van den Brincken, Studien zur lateinischen Weltchronistik bis in das Zeitalter Ottos von Freising. Düsseldorf 1957, 50-54; Schwarte, Vorgeschichte (wie Anm. 16), 148-152; Strobel, Imperium Romanum (wie Anm. 15), 116.

19 Hippolytos hatte die Geburt Christi in seinem Daniel-Kommentar zunächst in das Weltjahr 5500 datiert (Hippolyt. Dan. 4,23 [G. N. Bonwetsch (Ed.), Hippolyt. Werke I 1: Kommentar zu Daniel, 2. vollständig veränderte Auflage von M. Richard. Berlin 2000], 244-246), errechnete dann in seiner Chronik aber die leicht davon abweichende Zahl 5502 (A. Bauer/R. Helm [Edd.], Hippolytus. Werke, Bd. 4: Die Chronik. Berlin 1955, XXVIII). Dazu siehe u. a. J. Daniélou, La typologie millenariste de la semaine dans le christianisme primitif, VChr 2 (1948) 1-16, bes. 13; van den Brincken, Weltchronistik (wie Anm. 18), 54-57; Schwarte, Vorgeschichte (wie Anm. 16), 128-148; 152 158; G. Podskalsky, Byzantinische Reichseschatologie. Die Periodisierung der Weltgeschichte in den vier Großreichen (Daniel 2 und 7) und dem tausendjährigen Friedensreiche (Apok. 20) - eine motivgeschichtliche Untersuchung (Münchener Universitäts-Schriften, Reihe der Phil. Fak., 9). München 1972, 8-10, 79 f.; R. Landes, Lest the Millennium be Fulfilled: Apocalyptic Expectations and the Pattern of Western Chronography 100-800 CE, in: W. Verbeke/D. Verhelst/A. Welkenhuysen (Hgg.), The Use and Abuse of Eschatology in the Middle Ages (Mediaevalia Lovaniensia, ser. I/15). Leuven 1988, 137-211., bes. 144 ff.; Strobel, Imperium Romanum (wie Anm. 15), 117.

20 H. Gelzer, Sextus Julius Africanus und die byzantinische Chronographie, II. Leipzig 1898, 189 ff.; A. Vasiliev, Medieval Ideas of the End of the World: West and East, Byz 16 (1942/43) 462-502, bes. 467-470; V. Grumel, La chronologie (Traité d'études byzantines, 1). Paris 1958, 73 ff., 85 ff.; B. Croke, Byzantine Chronicle Writing. 1: The Early Developments of Byzantine Chronicles, in: E. Jeffreys/B. Croke/R. Scott (Hgg.), Studies in John Malalas (Byzantina Australiensia, 6). Sydney 1990, 27-38, bes. 32-35; Brandes, Anastasios (wie Anm. 11), 29 f. 
(,Auferstehung') verweisenden Namen Anastasios trug. ${ }^{21}$ Wer hätte da nicht davon ausgehen sollen, daß die chronologischen Modelle zutreffend waren und die letzten Zeiten angebrochen waren?

Ich will dafür nur kurz einige Beispiele anführen: $:^{22}$ In der sog. Tübinger Theosophie, einem Textfragment mit orakelartigen Sprüchen aus der Zeit des Kaisers Zenon (474/75; 476-491), wird die unmittelbar bevorstehende Parusie Christi explizit mit dem Ablauf der 6000 Jahre begründet, ${ }^{23}$ und das um 503/04 verfaßte Orakel von Baalbek sagt das Weltende für die Zeit vor 510 bzw. nach dem Tod des Kaisers Anastasios voraus, der in diesem Text bereits als Endzeitkaiser gekennzeichnet ist. ${ }^{24}$ Auch die nicht erhaltene griechische Vorlage einer armenischen Apokalypse mit dem Titel Die siebte Vision Daniels gehört in die Zeit um 500. ${ }^{25}$ Syrische Chroniken des 7., 8. und 9. Jahrhunderts bringen die Herrschaft des Anastasios mit dem Ablauf der 6000 Jahre in Verbindung, ${ }^{26}$ und noch im 12. Jahrhundert konstatiert der Chronist Michael Syrus unter Berufung auf zeitgenössisches Material eine allgemein verbreitete Erwartung des

21 Zu den Naturkatastrophen im 6. Jh. und zur eschatologischen Konnotation des Namens ,Anastasios' siehe Meier, Zeitalter (wie Anm. 11), $45 \mathrm{ff}$., $67 \mathrm{ff}$., $656 \mathrm{ff}$.

22 Eine ausführliche Diskussion der wichtigsten Zeugnisse bietet Brandes, Anastasios (wie Anm. 11), 53 ff.; vgl. auch dens., Die apokalyptische Literatur, in: F. Winkelmann/W. Brandes (Hgg.), Quellen zur Geschichte des frühen Byzanz (4.-9. Jahrhundert). Bestand und Probleme (BBA 55). Berlin 1990, 305-322, bes. $308 \mathrm{ff}$.

23 Theos. Tubing. $\$ 2-3(=\mathrm{H}$. Erbse [Ed.], Theosophorum Graecorum Fragmenta. Stuttgart/Leipzig $\left.{ }^{2} 1995,1-2\right)$.

24 Baalbek-Orakel p. 14,94-95; 19,173-22,227; bes. 19,161-166 (= P. J. Alexander, The Oracle of Baalbek. The Tiburtine Sibyl in Greek Dress [DOS 10]. Washington 1967). Dazu Brandes, Apokalyptische Literatur (wie Anm. 22), 309; ders., Anastasios (wie Anm. 11), 57 ff.; Al. Cameron, Oracles and Earthquakes. A Note on the Theodosian Sibyl, in: C. Sode/S. Takács (Hgg.), Novum Millennium: Studies on Byzantine History and Culture Dedicated to Paul Speck. Aldershot 2001, 45-52; Meier, Zeitalter (wie Anm. 11), $67 \mathrm{ff}$.

25 Text und deutsche Übersetzung: P. G. Kalemkiar, Die siebente Vision Daniels, WZKM 6 (1892), 109-136, 227-240, mit der wohl unzutreffenden Datierung des griechischen Originals in das 7. Jh. (114); zur Datierung in die Zeit um 500 siehe Alexander, Oracle of Baalbek (wie Anm. 24), 118 mit Anm. 74; Brandes, Apokalyptische Literatur (wie Anm. 22), 310 mit Anm. 2; ders., Anastasios (wie Anm. 11), 54. - Möglicherweise beruht der Verweis auf die endzeitliche Rolle des Anastasios und den Ablauf der 6000 Jahre unter seiner Herrschaft in der nach 912 verfaßten Chronik des Petros von Alexandreia (Z. G. Samodurova, Chronika Petra Aleksandrijskogo, VV 18 [1961] 150197 [Text: 180-197], hier 195,38-196,7) auf einer Vorlage aus der Zeit um 500 (vgl. Brandes, Anastasios, 55).

26 So das Chronicon Melciticum 12 (= A. de Halleux [Ed.], La chronique melkite abrégée du ms. Sinaï syr. 10, Le Muséon 91 [1978] 5-44, hier 30), ferner eine anonyme Chronik aus der 2. Hälfte des 8. Jh. (Incerti Auctoris Chronicon Pseudo-Dionysianum vulgo dictum I, interpretatus est J.-B. Chabot [CSCO 121; Scr. Syri III/1]. Louvain 1949 , 12) und das Chronicon ad annum 846 (Chronica Minora II, interpretatus est I.-B. Chabot [CSCO 4; Scr. Syri 4]. Louvain 1904 [ND 1955], 166). 
Weltendes um 500, weil die 6000 Jahre abgelaufen seien. ${ }^{27}$ In welch hohem Maße diesen Erwartungen in der Tat die seit dem 3. Jahrhundert verstärkt betriebenen chronologischen Kalkulationen zugrunde lagen, geht vor allem aus der Chronik des Johannes Malalas hervor, der eine seiner Hauptaufgaben darin sah, die Valenz entsprechender Berechnungen zu widerlegen, indem er ihnen eine eigene Chronologie entgegenstellte, die auch andernorts belegt und in der Forschung als sog. Antiochenisches Modell bekannt ist. ${ }^{28}$

Es waren also vor allem christliche Chronologien, die in der Zeit um 500 verbreitete Endzeitängste auslösten, und es waren die gleichzeitig einsetzenden Naturkatastrophen und weitere Faktoren, wie z.B. der Name des Kaisers Anastasios, die entsprechende Erwartungen dann zu bestätigen schienen.

Wie sah nun die Situation im Westen aus? Erstaunlicherweise ganz anders. Zwar gibt es vereinzelte Belege für Endzeiterwartungen um 500 im Werk des Alcimus Avitus, ${ }^{29}$ zwar besitzen wir kleinere Chroniken, in denen für die Jahre vor 500 Gerüchte über die Geburt des Antichrist und den Ablauf der 6000 Jahre verzeichnet sind ${ }^{30}$ aber das ist letztlich auch beinahe alles. ${ }^{31}$ Insgesamt jedenfalls kann man die Beleglage nicht mit dem Material vergleichen, das uns für den-

27 Mich. Syr. 9,11 (J.-B. Chabot, Chronique de Michel le Syrien, Patriarche Jacobite d'Antioche [1166-1199], II. Paris 1901 [ND Brüssel 1963], 167 f.).

28 E. Jeffreys, Chronological Structures in Malalas' Chronicle, in: Jeffreys/Croke/Scott, Studies in John Malalas (wie Anm. 20), 111-166; dies., The Beginning of Byzantine Chronography: John Malalas, in: G. Marasco (Hg.), Greek and Roman Historiography in Late Antiquity. Fourth to Sixth Century A.D. Leiden/Boston 2003, 497-527, 513515; M. Meier, Zur Neukonzeption chronologisch-eschatologischer Modelle im oströmischen Reich des 6. Jh. n. Chr. Ein Beitrag zur Mentalitätsgeschichte der Spätantike, in: W. Geerlings (Hg.), Der Kalender. Aspekte einer Geschichte. Paderborn u.a. 2002, 151-181, bes. 159 ff.; ders., Zeitalter (wie Anm. 11), 444 ff. Zu den weiteren Hinweisen auf das ,Antiochenische Modell' in den Quellen siehe ebenda $455 \mathrm{ff}$.

29 Alc. Avit. epist. 21 (R. Peiper [Ed.], Alcimi Ecdicii Aviti Viennensis Episcopi Opera quae supersunt. Berlin 1883 [ND 1961] [MGH AA VI 2], 54,3-13); siehe auch epist. 22 - p. 54,14-55,9; epist. 30 - p. 60,12-15; epist. 34 - p. 64,30; carm. 5,231-259.

30 Paschale Campanum ad a. 493; 496 (Th. Mommsen [Ed.], Chronica Minora Saec. IV. V. VI. VII., I. Berlin 1892 [ND München 1981] [MGH AA IX], 746 f.); Fasti Vindobonenses Posteriores ad a. 495 - p. 330; [Prosper Tiro] De Enoc et Helia p. 493.

31 Vgl. Landes, Apocalyptic Expectations (wie Anm. 19), 161: „Indeed, by 500 CE we have no document recognizing the arrival of the year 6000, no history dating by AM I [dem Modell des Africanus/Hippolytos, M.M.], and no particular evidence of apocalyptic panic“. Ähnlich van den Brincken, Weltchronistik (wie Anm. 18), 65. Immerhin zeigt die Existenz diverser Apokalypse-Kommentare (z. B. von Primasius; vgl auch Caesarius von Arles), daß man sich weiterhin rege mit der Frage nach dem Weltende beschäftigte; zu diesen Kommentaren siehe Landes, Apocalyptic Expectations, 164 mit Anm. 112. Siehe auch die umfassende Übersicht bei R. Gryson, Les commentaires patristiques latins de l'Apocalypse, Revue théologique de Louvain 28 (1997) 305-337, 484-502. 
selben Zeitraum aus dem Osten vorliegt - weder quantitativ noch qualitativ. ${ }^{32}$ Woran liegt das?

Um das Ergebnis vorwegzunehmen: Die chronologischen Modelle, auf denen die Endzeiterwartungen im Osten ganz wesentlich basierten, haben für den Westen um 500 nur eine ganz marginale Rolle gespielt - obwohl dies noch um 400 n. Chr. anders war: Die Chronographen Q. Iulius Hilarianus (ca. 397) und Sulpicius Severus (ca. 404) etwa folgten noch dem von Africanus und Hippolytos errechneten Modell, als sie das Weltende um 500 ansetzten, ${ }^{33}$ und noch im 1. Viertel des 5. Jahrhunderts finden wir dieselbe Kalkulation im Liber Genealogus. ${ }^{34}$ Es war dann allerdings dem Einfluß der Autoritäten Hieronymus und Augustinus geschuldet, daß dieses Modell im Westen seit dem frühen 5. Jahrhundert erheblich an Einfluß verlor und daß das Jahr 500 dementsprechend im Westen eschatologisch weit weniger bedeutend gewesen ist als im Osten.

Bereits Eusebios von Kaisareia hatte im frühen 4. Jahrhundert in seiner Chronik eine alternative Kalkulation vorgelegt, wonach der Beginn des irdischen Wirkens Jesu in das Weltjahr 5228 zu datieren sei - womit das Weltende sich entsprechend verschoben hätte. ${ }^{35}$ Allerdings hat der unter dem Einfluß des

$32 \mathrm{Zu}$ letzterem ist allerdings einschränkend hinzuzufügen, daß es prinzipiell ausgesprochen schwierig ist, aus dem vorliegenden Material sichere Schlußfolgerungen auf Breitenwirkung und Repräsentativität der apokalyptischen Texte zu ziehen. Unbestreitbar ist allerdings auch die Tatsache, daß für den Westen um $500 \mathrm{n}$. Chr. Zeugnisse wie etwa die Kontakien des Romanos Melodos, die auf eine große Verbreitung aktueller Endzeitängste schließen lassen, schlichtweg nicht vorliegen. Dies nur auf Überlieferungszufälle zurückzuführen, erscheint mir zu einfach. Denn auch die Quellen für Endzeiterwartungen um $500 \mathrm{im}$ Osten haben sich in recht großer Zahl erhalten, obwohl sie durch das Fortbestehen der irdischen Welt letztlich ja widerlegt und damit überflüssig bzw. uninteressant geworden waren, denn „nichts ist obsoleter als eine Schrift, die das Ende der Welt voraussagt, nachdem das angegebene Datum vergangen ist“ (Brandes, Anastasios [wie Anm. 11], 62).

33 Hilarianus, De cursu temporum 18, PL 13, 1105 f.; C. Frick (Ed.), Chronica Minora, I. Leipzig 1892, 153-174, hier 171,5-14; dazu Gelzer, Africanus II (wie Anm. 20), 121 129; van den Brincken, Weltchronistik (wie Anm. 18), 57-60; Kötting, Endzeitprognosen (wie Anm. 16), 129 f.; Schwarte, Vorgeschichte (wie Anm. 16), 169-176; Landes, Apocalyptic Expectations (wie Anm. 19), 152; Brandes, Anastasios (wie Anm. 11), 31. - Sulpicius Severus: Sulp. Sev. Vita Martini 24,3 (C. Halm [Ed.], Sulpicii Severi Libri qui supersunt [CSEL 1]. Wien 1866, 133); Dial. 2,14,4 (a.a.O., 197); chron. 2,27,2 (a.a.O., 82); 2,33,2-4 (a.a.O., 87); dazu Kötting, Endzeitprognosen 129; J. Vaesen, Sulpice Sévère et la fin des temps, in: Verbeke/Verhelst/Welkenhuysen, The Use and Abuse of Eschatology (wie Anm. 19), 49-70; St. Weber, Die Chronik des Sulpicius Severus. Charakteristika und Intentionen. Trier 1997.

34 Liber Genealogus: Th. Mommsen [Ed.], Chronica Minora I, MGH AA IX. Berlin 1892, 154-196, bes. 194-195; vgl. Landes, Apocalyptic Expectations (wie Anm. 19), 153.

35 Van den Brincken, Weltchronistik (wie Anm. 18), 60 ff.; Landes, Apocalyptic Expectations (wie Anm. 19), 149. Eusebios setzt die Vicennalien Konstantins (325 n. Chr.) in 
Origenes stehende Eusebios es ohnehin vermieden, von einem konkreten Zeitpunkt des Weltendes zu sprechen, da er materialistisch-millenaristische Spekulationen grundsätzlich ablehnte. ${ }^{36} \mathrm{Im}$ griechischsprachigen Osten fand das eusebianische Modell nur wenig Zustimmung, nicht einmal die griechische Originalversion seiner Chronik ist erhalten geblieben. Dagegen war sein Einfluß auf das eschatologische Denken im Westen beträchtlich, denn im Jahr 379 übersetzte Hieronymus die Chronik des Eusebios ins Lateinische und „through this translation, Eusebius' chronological format, data and calculations became the foundation of all orthodox Western historiography “ ${ }^{37}$ Auch der erwähnte Rückgriff auf das von Africanus und Hippolytos errechnete Modell durch Autoren wie Hilarianus und Sulpicius Severus um 400 konnte den Siegeszug der von Eusebios/Hieronymus propagierten Kalkulation nicht mehr verhindern. Im 6. Jahrhundert jedenfalls datierte im Westen niemand mehr außer dem oströmisch sozialisierten Jordanes nach dem ursprünglichen Modell. ${ }^{38}$ Dafür kam es dann zu verstärkten Endzeiterwartungen, als die Kalkulation des Eusebios/ Hieronymus ihrerseits die Grenze der 6000 Jahre erreicht hatte: Im Kontext der Kaiserkrönung Karls des Großen im Jahr 800. ${ }^{39}$

Die Frage, warum sich zu Beginn des 5. Jahrhunderts im Westen ausgerechnet die von Eusebios/Hieronymus vertretene Alternative durchgesetzt hat, ist nicht leicht zu beantworten. Die Autorität eines Hieronymus mag dabei eine wichtige Rolle gespielt haben, ferner die Tatsache, daß offenbar auch um 400 vielfach konkrete Endzeitängste bestanden, von denen sich sogar Hieronymus phasenweise nicht ganz befreien konnte und deren ausbleibende Erfüllung ge-

das Weltjahr 5526, vgl. R. W. Burgess, Studies in Eusebian and Post-Eusebian Chronography (Historia-Einzelschriften, 135). Stuttgart 1999, 64.

36 Landes, Apocalyptic Expectations (wie Anm. 19), 149 f.: „strategy of denial by ommission" (150); vgl. auch Podskalsky, Reichseschatologie (wie Anm. 19), 82 f.

37 Landes, Apocalyptic Expectations (wie Anm. 19), 151; vgl. auch ebenda 165; ähnlich Gelzer, Africanus II (wie Anm. 20), 23; vgl. auch F. Winkelmann, Historiography in the Age of Constantine, in: Marasco, Greek and Roman Historiography (wie Anm. 28), 3 41, bes. 20 .

38 Iord. Rom. 10. Siehe van den Brincken, Weltchronistik (wie Anm. 18), 89; Landes, Apocalyptic Expectations (wie Anm. 19), 139, 165 mit Anm. 113. Zum oströmischen Hintergrund des Jordanes siehe auch W. Goffart, The Narrators of Barbarian History (A.D. 550-800). Jordanes, Gregory of Tours, Bede, and Paul the Deacon. Princeton 1988, 42-47, bes. 46. Die geringen Spuren, die die Kalkulation des Africanus/Hippolytos im 5. Jh. im Westen hinterlassen hat, behandelt Landes, Apocalyptic Expectations (wie Anm. 19), 162.

39 Dazu siehe Landes, Apocalyptic Expectations (wie Anm. 19), 191 ff.; Brandes, Anastasios (wie Anm. 11), 27; ders., „Tempora periculosa sunt“. Eschatologisches im Vorfeld der Kaiserkrönung Karls des Großen, in: R. Berndt (Hg.), Das Frankfurter Konzil von 794. Kristallisationspunkt karolingischer Kultur, Teil 1: Politik und Kirche. Mainz 1997, 49-79, 49 ff.; J. Heil, „Nos nescientes de hoc velle manere“ - „We wish to remain ignorant about this“: Timeless End, or: Approaches to Reconceptualizing Eschatology after A.D. 800 (A.M. 6000), Traditio 55 (2000) 73-103, bes. 73 ff. 
nerelle Neuorientierungen erleichtert haben könnte. ${ }^{40}$ Vor allem aber dürfte sich der Einfluß Augustins maßgeblich ausgewirkt haben, der zumindest implizit auf das eusebianische Modell zurückgegriffen hat. ${ }^{41}$ Augustin setzte sich energisch gegen millenaristische Spekulationen und gegen die eschatologisch-apokalyptische Interpretation konkreter irdischer Ereignisse zur Wehr. ${ }^{42}$ Ein wohlberatener Christ habe sich von derartigen Gedanken freizumachen. ${ }^{43}$ Stattdessen gliederte er - im Rückgriff auf ältere Periodisierungen der römischen Geschichte ${ }^{44}-$ nunmehr die Weltgeschichte analog der Lebenszeit eines Menschen in sechs Zeitalter, wobei die Gegenwart in das letzte Zeitalter falle, das mit der Menschwerdung Christi begonnen habe. Obwohl Augustin keine konkrete Dauer dieses 6. Zeitalters angeben wollte (Isidor von Sevilla hat entsprechende Spekulationen später sogar ausdrücklich verboten), ${ }^{45}$ ließ er allein durch die

40 Die wichtigsten Zeugnisse dafür hat Kötting, Endzeitprognosen (wie Anm. 16), 130 ff., zusammengestellt; vgl. auch Landes, Apocalyptic Expectations (wie Anm. 19), 153156; Meier, Zeitalter (wie Anm. 11), 15 f. Zu den Ängsten des Hieronymus siehe etwa Hieron. epist. 123,15-16 (I. Hilberg [Ed.], Sancti Eusebii Hieronymi Epistulae, III [CSEL 56]. Wien/Leipzig 1918, 91,17-94,13); Hieron. In Ezech. VIII praef. (F. Glorie [Ed.], S. Hieronymi Presbyteri Commentariorum in Hiezechielem Libri XIV [CCSL 74]. Turnhout 1964, 333); O. Zwierlein, Der Fall Roms im Spiegel der Kirchenväter, ZPE 32 (1978) 45-80, bes. 49; B. Feichtinger, Glaube versus Aberglaube. Der Untergang Roms in den Augen von Zeitgenossen, in: Chartulae. Festschrift für Wolfgang Speyer (JbAC Ergänzungsb. 28). Münster 1998, 145-166.

41 Landes, Apocalyptic Expectations (wie Anm. 19), 157, $159 \mathrm{f}$.

42 Vgl. P. Fredriksen, Apocalypse and Redemption in Early Christianity. From John of Patmos to Augustine of Hippo, VChr 45 (1991) 151-183, bes. 160 ff. Allerdings lassen sich noch beim frühen Augustin gewisse Sympathien für chiliastische Theorien ausmachen, denen zufolge nach den 6000 Jahren der irdischen Weltzeit eine längere Herrschaftszeit Gottes anbreche, z. B. Augustin. hom. 259,2, PL 38, 1197; ablehnend dann aber etwa Augustin. civ. 20,7; 20,21; epist. 197-199 (Al. Goldbacher [Ed.], S. Aureli Augustini Hipponiensis Episcopi Epistulae, IV [CSEL 57]. Wien/Leipzig 1911, $231-$ 292). Vgl. dazu G. Folliet, La typologie du sabbat chez saint Augustin: son interprétation millénariste entre 389 et 400, Revue des études augustiniennes 2 (1956) 371-390.

43 Landes, Apocalyptic Expectations (wie Anm. 19), 156-158. Trotz allem sind auch nach Hieronymus und Augustin weiterhin immer wieder akute Endzeitängste greifbar (u.a. bei Augustins Schüler Quodvultdeus), vgl. Landes a.a.O., 158 f.; Fredriksen, Apocalypse (wie Anm. 42), 167; R. W. Burgess, The Chronicle of Hydatius and the Consularia Constantinopolitana. Two Contemporary Accounts of the Final Years of the Roman Empire. Oxford 1993, $9 \mathrm{f}$.

44 Etwa Cic. rep. 2,1,3; 2,11,21; Lact. inst. 7,15,14-17 (im Rückgriff auf Seneca); Flor. epit. praef. 4-8; Amm. 14,6,3-6. Zur Verwendung und Entwicklung entsprechender Lehren in der römischen Literatur vgl. R. Häussler, Vom Ursprung und Wandel des Lebensaltervergleichs, Hermes 92 (1964) 313-341; Schwarte, Vorgeschichte (wie Anm. 16), 43 ff.; A. Demandt, Metaphern für Geschichte. Sprachbilder und Gleichnisse im historisch-politischen Denken, München 1978, $37 \mathrm{ff}$.

45 Vgl. Isid. Sev. chron. 418 (Th. Mommsen [Ed.], Chronica Minora II. MGH AA XI. Berlin 1894, 481): Residuum saeculi tempus humanae investigationis incertum est. omnem 
Tatsache, daß er die Gegenwart gerade dort ansiedelte, dennoch Raum für weitere eschatologische Spekulationen. ${ }^{46}$ Dieser Raum wurde auch weiterhin fleißig ausgenutzt, die Zeit um 500 verlor dabei aber die große Bedeutung, die sie im Osten besaß. ${ }^{47}$

Halten wir also fest: Während um das Jahr 500 im Osten konkrete und weit verbreitete Endzeitängste offenbar einen wichtigen Bestandteil der Alltagserfahrung und -bewältigung ausmachten, sah dies im Westen ganz anders aus. Auf dem für alle Christen so zentralen Gebiet der Eschatologie besaßen die beiden Reichshälften offenbar keine gemeinsame Basis mehr.

III.

Begeben wir uns in einem nächsten Schritt in das spätere 6. Jahrhundert und werfen wir wiederum zunächst einen Blick auf den Osten. Dort zeichnet sich deutlich eine interessante Tendenz ab: Die Zeugnisse für akute Endzeiterwartungen werden seltener. Zwar besitzen wir weiterhin unmißverständliche Hinweise auf konkrete apokalyptische Ängste, etwa im Kontext des Ausbruchs der Pest $541 / 42^{48}$ oder des schweren Erdbebens in Konstantinopel 557, ${ }^{49}$ aber solche Zeugnisse werden zunehmend punktuell, und insgesamt gesehen läßt sich der diesbezügliche Quellenbestand nicht mehr mit dem Material für die Zeit

enim de hac re quaestionem dominus Iesus Christus abstulit dicens: 'non est vestrum nosse tempora vel momenta, quae pater posuit in sua potestate' [...].

46 Augustin. De Genesi adversus Manichaeos 1,35-41; civ. 22,30. Vgl. Th. Fuhrer, Augustinus. Darmstadt 2004, 148 f.; ausführlich Schwarte, Vorgeschichte (wie Anm. 16), 17 ff.; B. Kötting/W. Geerlings, Augustinus-Lexikon 1 (1986-1994) 150-158 (s.v. aetas).

47 Landes, Apocalyptic Expectations (wie Anm. 19), 161, vermutet darüber hinaus, daß aufgrund des prinzipiellen Verdikts Augustins gegenüber millenaristischen, auf das Jahr 500 hin zugespitzten Spekulationen entsprechende Texte, auch wenn sie vielleicht ursprünglich existiert haben mögen, schlichtweg nicht mehr kopiert worden seien.

48 Etwa Malal. p. 481,3-21 (L. Dindorf [Ed.], Ioannis Malalae Chronographia, Bonn $1831)=$ p. 406,87-407,8 (I. Thurn [Ed.], Ioannis Malalae Chronographia [CFHB 35]. Berlin/New York 2000); Vita Nicolai Sionitae 47-53 (H. Blum [Ed./Übers.], Die Vita Nicolai Sionitae. Bonn 1997, p. 64-70); auch die ausführliche Pestbeschreibung des Johannes von Ephesos (in: W. Witakowski [Übers.], Pseudo-Dionysios of TelMahre. Chronicle, Part III [Translated Texts for Historians, 22]. Liverpool 1996, 74-98 = A. Harrak [Übers.], The Chronicle of Zuqnîn, Parts III and IV A.D. 488-775. Toronto 1999, 94-113) ist in einem streng apokalyptischen Ton gehalten, rekurriert aber vor allem auf alttestamentliche Strafprophetien. Vgl. Meier, Zeitalter (wie Anm. 11), 321 ff.; ders., „Hinzu kam auch noch die Pest ...“. Die sogenannte Justinianische Pest und ihre Folgen, in: M. Meier (Hg.), Pest. Die Geschichte eines Menschheitstraumas. Stuttgart 2005, 86-107, 396-400.

49 Agath. hist. 5,3-9, bes. 5 (Agathiae Myrinaei Historiarum libri quinque, rec. R. Keydell [CFHB 2]. Berlin 1962, 166-175); dazu Meier, Zeitalter (wie Anm. 11), 405 ff. 
um 500 vergleichen. Trotzdem - und das ist mir wichtig - wurde aber offenbar weiterhin erregt über das Weltende bzw. über damit zusammenhängende eschatologische Probleme diskutiert (dies zeigt sich schon daran, daß entsprechende Befürchtungen zu bestimmten Anlässen plötzlich wieder hervorbrechen konnten) - und zwar deshalb, weil die Parusie nicht zum erwarteten Zeitpunkt erfolgt war, weil dies erklärt werden mußte und weil die Konsequenzen für die gängigen chronologischen und eschatologischen Modelle nun zu erörtern waren. In diesen Kontext gehören u.a. neuerliche chronologische Spekulationen, die sich nahezu zwangsläufig auch mit der alten Frage der korrekten Berechnung des Ostertermins verquicken mußten ${ }^{50}$ aber auch die nunmehr entstehenden ersten griechischen Kommentare zur Offenbarung des Johannes (Oikumenios, Andreas von Kaisareia) hatten sich mit diesem Problem zu beschäftigen, und selbst der vielfach als naiv geltende Kaufmann Kosmas Indikopleustes räsonnierte über eschatologische Fragen, die sich aus der skizzierten Situation ergeben hatten. ${ }^{51}$ Deutlich sind entsprechende Diskussionen auch in der syrischen Literatur faßbar, wo vereinzelt die Variante einer ,Aufstockung' der 6000 Jahre auf 7000 Jahre diskutiert wurde. ${ }^{52}$ Gerade solche Debatten um das Weltende, wie sie im späteren 6. Jahrhundert im Osten ganz offenkundig geführt wurden, machen damit ein weiteres Mal deutlich, in welch hohem Maße dort die verbreitete Weltuntergangsstimmung um 500 auf den geläufigen chronologischen Kalkulationen basiert hatte. Erst im 7. Jahrhundert waren es im Osten aktuelle Zeiterfahrungen (persische Besetzung byzantinischer Territorien; Fall Jerusalems 614; Angriff der Araber seit 634), die wieder zu konkreteren Endzeitängsten führten..$^{53}$

50 Vgl. zu diesem Komplex Meier, Zeitalter (wie Anm. 11), 443 ff., bes. 466 ff. (zu den Diskussionen über den Ostertermin).

51 Podskalsky, Reichseschatologie (wie Anm. 19), 16-19 (Kosmas), 84-88 (Oikumenios, Andreas); Meier, Zeitalter (wie Anm. 11), 478-481.

52 P. Bruns, Endzeitberechnungen in der syrischen Kirche, in: Geerlings, Kalender (wie Anm. 28), 122-139, bes. 128 ff.; Meier, Zeitalter (wie Anm. 11), 460 f.

53 Die Endzeitängste, die mit dem byzantinisch-persischen Krieg einhergingen, scheinen sich in dem sog. Chosroes-Vatizinium (Theophyl. Sim. 5,15 [Theophylacti Simocattae historiae, ed. C. de Boor. Stuttgart 1972, 216-218]; dazu siehe G. J. Reinink, Heraclius, the New Alexander. Apocalyptic Prophecies during the Reign of Heraclius, in: G. J. Reinink/B. H. Stolte [Hgg.], The Reign of Heraclius (610-641). Crisis and Confrontation [Groningen Studies in Cultural Change, 2]. Leuven 2002, 81-94, bes. $87 \mathrm{ff}$.) und in der Golinduch-Geschichte (Theophyl. Sim. 5,12 [ed. de Boor, 210-212]) zu spiegeln. Für die apokalyptischen Befürchtungen, die sich mit der Araberinvasion verbanden, stellt die Apokalypse des Ps.-Methodios das bekannteste Zeugnis dar, vgl. Brandes, Apokalyptische Literatur (wie Anm. 22), 310 ff.; H. Möhring, Der Weltkaiser der Endzeit. Entstehung, Wandel und Wirkung einer tausendjährigen Weissagung (Mittelalter-Forschungen, 3). Stuttgart 2000, $54 \mathrm{ff}$. 
Und einmal mehr sieht die Situation im Westen ganz anders aus. Denn anders als zu Beginn des 6. Jahrhunderts scheint das Endzeitproblem jetzt zumindest im merowingischen Gallien und im langobardisch-byzantinischen Italien eine gesteigerte Bedeutung besessen zu haben. Der wohl prominenteste Exponent dieser akuten Naherwartungen dürfte Papst Gregor der Große (590604) gewesen sein, ${ }^{54}$ der überall die Vorzeichen des nahenden Endes um sich wähnte. ${ }^{55}$ Noch sein Biograph Johannes Diaconus konnte im 9. Jahrhundert festhalten: „Und so beschäftigte sich Gregor in all seinen Worten wie Taten mit dem drohenden jüngsten Tag des zukünftigen Strafgerichts, und je vorsichtiger er alle Aspekte von allem erwog, desto näher nahm er das bevorstehende Ende der Welt wahr, da die Signale für ihren Untergang zunahmen “. ${ }^{56}$ Und in der Tat spiegeln nicht nur Gregors Schriften eine permanente Erwartung des unmittelbar bevorstehenden Weltendes, sondern auch sein Wirken als Papst stand ganz unter diesem Zeichen. Der Aristokrat aus angesehener senatorischer Familie hatte es wohl bereits ca. 572/573 zum Stadtpräfekt Roms gebracht, bevor er sich kurz darauf in die mönchische Einsamkeit zurückzog - möglicherweise, um sich spirituell auf das Weltende vorzubereiten. ${ }^{57}$ Im Jahr 590 jedoch starb Papst Pelagius II. an der Pest, die Rom damals in verheerender Weise heimsuchte, und Gregor wurde - angeblich gegen seinen Willen - zu seinem Nachfolger gewählt. ${ }^{58}$ Von nun an sah er eine seiner Hauptaufgaben u. a. darin, seine Zeitgenossen zur Buße vor Gott anzuleiten, um dadurch möglichst viele von ihnen vor der mit dem jüngsten Tag hereinbrechenden Verdammnis zu bewahren. Gleich die erste spektakuläre Aktion des designierten Papstes, der

$54 \mathrm{Zu}$ Gregor dem Großen siehe vor allem die Monographie von R. A. Markus, Gregory the Great and His World. Cambridge 1997. Einen kurzen Überblick bietet R. Manselli, RAC 12 (1983) 930-951 (s.v. Gregor der Große V). Daneben siehe auch J. Richards, Gregor der Große. Sein Leben, seine Zeit. Graz/Wien/Köln 1983; H. Leppin, Die Kirchenväter und ihre Zeit. München 2000, 101-111.

55 Leppin, Kirchenväter (wie Anm. 54), 109. Zur Endzeiterwartung Gregors siehe C. Dagens, La fin des temps et l'église selon Saint Grégoire le Grand, Recherches de science religieuse 58 (1970) 273-288 (mit den wichtigsten Belegstellen); R. E. McNally, Gregory the Great and His Declining World, AHP 16 (1978) 7-26; H. Savon, L'Antéchrist dans l'œuvre de Grégoire le Grand, in: J. Fontaine/R. Gillet/S. Pellistrandi (Hgg.), Grégoire le Grand. Paris 1986, 389-405; Markus, Gregory the Great (wie Anm. 54), 51 ff.; M. Simonetti, Gregorio Magno e la nascita dell'Europa, Vetera Christianorum 34 (1997) 311-327, bes. 313 f.; C. Ricci, Mysterium Dispensationis. Tracce di una teologia della storia in Gregorio Magno. Rom 2002.

56 Joh. Diac. Vita Greg. 4,65, PL 75, $214 \mathrm{AB}$.

57 So McNally, Gregory the Great (wie Anm. 55), 11; Prinz, Von Konstantin zu Karl dem Grossen (wie Anm. 4), $51 \mathrm{f}$.

$58 \mathrm{Zu}$ Gregors Karriere siehe im einzelnen Markus, Gregory the Great (wie Anm. 54), 814. Zur Wahl Gregors zum Papst siehe E. H. Fischer, Gregor der Große und Byzanz. Ein Beitrag zur Geschichte der päpstlichen Politik, ZRG kan. Abt. 67 (1950) 15-144, bes. $33 \mathrm{ff}$. 
damals noch nicht in sein Amt eingeführt worden war, spiegelt diese Haltung. Damals bedrohten die Langobarden die Stadt; eine Tiberflut hatte schwere Schäden angerichtet und eine Hungersnot ausgelöst, die Römer wollten in den Fluten sogar einen Drachen erblickt haben; und überdies war auch noch die Pest ausgebrochen. ${ }^{59}$ Um der Seuche Herr zu werden, beraumte Gregor eine Bußprozession zu Ehren der Gottesmutter an. Dieses Mittel der kollektiven Bewältigung einer Pestepidemie hatte er aller Wahrscheinlichkeit nach in Konstantinopel kennengelernt, wo er in den Jahren 579/80-586 als Vertreter des Papstes (Apokrisiar) geweilt hatte, wo er u.a. enge Beziehungen zu Kaiser Maurikios geknüpft und Einblick in die Bräuche im Osten erhalten hatte. ${ }^{60}$ Dort hatte Justinian im Jahr 542 im Kampf gegen die Pest die HypapanteProzession als Bußprozession zu Ehren Marias eingeführt. ${ }^{61}$ Gregor jedoch gestaltete die Anregungen, die er aus dem Osten mitgenommen hatte, zu einem ungleich universaleren Ereignis aus. Denn er sah in der Prozession vor allem die Gelegenheit, seine sündigen Zeitgenossen angesichts des drohenden Endes zur Buße zu bewegen. In sieben Zügen sollte sich die Bevölkerung Roms zur Kirche S. Maria Maggiore begeben. Hartmut Leppin hat angemerkt, daß die Ein-

59 Greg. Tur. Hist. 10,1 (Gregorii episcopi Turonensis Libri historiarum X, edd. B. Krusch - W. Levison, MGH. Scriptores rerum Merovingicarum, I/1. Hannover 1951, $477-$ 481); Paul. Diac. Hist. Lang. 3,24 (Pauli Historia Langobardorum, edd. L. Bethmann et G. Waitz, MGH, Scriptores rerum Langobardicarum et Italicarum. Hannover 1878, 104,22-105,14); Joh. Diac. Vita Greg. 1,34-37, PL 75, 77C-78B; vgl. Greg. epist. 1,3 (S. Gregorii Magni Registrum epistularum, I, ed. D. Norberg [CCSL 140]. Tournhout 1982, 3); Dial. 3,19 (Grégoire le Grand, Dialogues, éd. et rad. par A. de Vogüé/P. Antin, II [SC 260]. Paris 1979, 346-350); Markus, Gregory the Great (wie Anm. 54), 13. Vgl. C. Pietri, La Rome de Grégoire, in: Gregorio Magno e il suo tempo. XIX incontro di studiosi dell'antichità cristiana in collaborazione con l'École Française de Rome. Roma, 9-12 maggio 1990, I: Studi storici. Rom 1991, 9-32, bes. 9 ff.

60 Über Gregors Pestprozession im Jahr 590 berichtet ausführlich Greg. Tur. Hist. 10,1 (edd. Krusch/Levison [wie Anm. 59], 477-481); vgl. daneben auch Paul. Diac. Hist. Lang. 3,24 (ed. Waitz [wie Anm. 59], 104,22-105,14); Paul. Diac. Vita Greg. 10-11 (H. Grisar [Ed.], Die Gregorbiographie des Paulus Diakonus in ihrer ursprünglichen Gestalt, nach italienischen Handschriften, Zeitschrift für katholische Theologie 11 [1887] 158-173, hier 167-169); Joh. Diac. Vita Greg. 1,41-43, PL 75, 79C-81A. Vgl. noch H. H. Mollaret/J. Brossollet, La procession de saint Grégoire et la peste à Rome en l'an 590, Médicine de France 199 (1969) 13-22; M. Meier, Von Prokop zu Gregor von Tours. Kultur- und mentalitätengeschichtlich relevante Folgen der ,Pest ${ }^{`}$ im 6. Jahrhundert, in: K.-P. Jankrift/F. Steger (Hgg.), Gesundheit - Krankheit. Kulturtransfer medizinischen Wissens von der Spätantike bis in die Frühe Neuzeit. Köln/ Weimar/Wien 2004, 19-40, bes. 33 ff. (mit Begründung der These eines Imports der Pestprozession aus Konstantinopel durch Gregor den Großen); H. Leppin, Gregor der Große. Die heilsame Seuche, in: Meier (Hg.), Pest (wie Anm. 48), 108-116, 400-401.

61 Dazu M. Meier, Kaiserherrschaft und „Volksfrömmigkeit“ im Konstantinopel des 6. Jahrhunderts n. Chr. Die Verlegung der Hypapante durch Justinian im Jahr 542, Historia 51 (2002) 89-111; ders., Zeitalter (wie Anm. 11), 570 ff. 
teilung dieser Züge überhaupt nicht der traditionellen sozialen Schichtung der römischen Gesellschaft entsprach, sondern kirchlichen Kriterien folgte. ${ }^{62}$ Noch wichtiger scheint mir die Siebenzahl zu sein, die im Kontext der Prozession auch keine regionalen Bezüge (etwa zu den sieben Hügeln Roms) aufweist; allerdings ist sie für sich genommen bereits stark eschatologisch konnotiert. ${ }^{63}$ Der Historiker Gregor von Tours überliefert eine Predigt, die Papst Gregor anläßlich dieser Prozession, der septiformis laetania, ${ }^{64}$ gehalten haben soll und aus der sein Bestreben, die Römer zur Buße zu bewegen, klar hervorgeht: ${ }^{65}$ „Erwäget aber wohl“, mahnt dort der designierte Papst, „wie der vor dem Throne des strengen Richters erscheinen wird, dem nicht einmal die Zeit bleibt zu beweinen, was er getan hat. [...] Ein jeder also von uns wende sich zur Buße und beklage seine Sünden, solange es noch Zeit ist zu Tränen und bevor der Streich ihn trifft.“ Ganz in diesem Sinne ging es Gregor letztlich auch gar nicht darum, seine Mitbürger vor dem Tod, namentlich vor einem grauenhaften Pesttod, zu retten, sondern sein Ziel bestand darin, noch vor dem jüngsten Tag möglichst viele Sünder zu reuiger Umkehr zu bewegen. Und so ist es auch nicht verwunderlich, daß sich während der Prozession entsetzliche Szenen abgespielt haben sollen, die Gregor aber nicht an der konsequenten Durchführung seines Vorhabens hindern konnten. Gregor von Tours berichtet, „daß damals im Verlauf einer Stunde [...] achtzig Menschen zu Boden gestürzt und gestorben seien. Doch der

62 Leppin, Gregor der Große (wie Anm. 60), 114. Die Aufteilung der Züge entsprach der Gliederung des Kirchenvolks: Jeweils von Priestern angeführt zogen (1) der (sonstige) Klerus, (2) Äbte und Mönche, (3) Äbtissinnen und Nonnen, (4) Kinder, (5) Laien, (6) Witwen und (7) Ehefrauen in einzelnen Zügen zur Marienkirche, wo sich alle Teilprozessionen vereinigten, vgl. Greg. Tur. Hist. 10,1 (edd. Krusch/Levison [wie Anm. 59], 480,13-481,6); Paul. Diac. Hist. Lang. 3,24 (ed. Waitz [wie Anm. 59], 105,9-12); Joh. Diac. Vita Greg. 1,42 (PL 75, 80D-81A).

63 H. Giesen, Die Offenbarung des Johannes. Übersetzt und erklärt. Regensburg 1997, $156 \mathrm{f}$., bes. 157: „In der Offb ist die Zahl sieben die Zahl der Geschehnisse in der Endzeit schlechthin“. Vgl. auch W. Brandes, Sieben Hügel: Die imaginäre Topographie Konstantinopels zwischen apokalyptischem Denken und moderner Wissenschaft, Rechtsgeschichte 2 (2003) 58-71.

64 So die Bezeichnung der Prozession bei Greg. Tur. Hist. 10,1 (edd. Krusch/Levison [wie Anm. 59], 480,10); Paul. Diac. Hist. Lang. 3,24 (ed. Waitz [wie Anm. 59], 105,7 f.); Paul. Diac. Vita Greg. 11 (ed. Grisar [wie Anm. 59], 168-169); Joh. Diac. Vita Greg. 1,41 (PL 75, 80C).

65 Greg. Tur. Hist. 10,1 (edd. Krusch/Levison [wie Anm. 59], 479,10-14; Übersetzung von W. Giesebrecht): Pensate ergo, qualis ad conspectum districti Iudicis pervenit, cui non vacat flere quod fecit. [...] Unusquisque ergo nostrum ad paenitentiae lamenta confugiat dum flere ante percussionem vacat. Vgl. Paul. Diac. Vita Greg. 11 (ed. Grisar [wie Anm. 59], 167-169). Gegen die vereinzelt geäußerten Bedenken hinsichtlich der Authentizität der Predigt (vgl. O. Chadwick, Gregory of Tours and Gregory the Great, JThS 50 [1949] 38-49) vgl. M. Heinzelmann, Gregor von Tours (538-594). ‘Zehn Bücher Geschichter. Historiographie und Gesellschaftskonzept im 6. Jahrhundert. Darmstadt 1994, 206 Anm. 83. 
künftige Bischof hörte nicht auf das Volk zu ermahnen, es solle im Gebete nicht nachlassen" ${ }^{66}$ Es ging also gar nicht um das Überleben in Zeiten der Pest, sondern um das ewige Leben nach dem Weltende, das u.a. durch die Pest angekündigt wurde. ${ }^{67}$

Buße und Erlösung angesichts des jüngsten Tages - dies sind Grundgedanken, auf die man immer wieder in Gregors Schriften trifft. Im November desselben Jahres 590 predigte Gregor vor den Römern über die Lukas-Apokalypse (Lk 21,25-33). In diesem Text findet seine konkrete Naherwartung nunmehr deutlichsten Ausdruck, und hier zeigt sich zudem, daß es vor allem die desolaten äußeren Umstände waren, die Gregor so intensiv auf das Ende der Welt blicken ließen: Hunger, Seuchen und andere Naturkatastrophen, dazu die Langobardeninvasion in Italien und die permanente Bedrohung Roms hatten ihm den Glauben an ein Weiterbestehen der irdischen Welt genommen. Der allseits manifeste Niedergang Roms war für ihn, den Senator und Mönch, das deutlichste Signal für das drohende Ende, denn Rom war in seinen Augen die Welt. ${ }^{68}$ Die apokalyptischen Zeichen, von denen der Evangelist spricht, sieht der Papst erfüllt: ${ }^{69}$

66 Greg. Tur. Hist. 10,1 (ed. Krusch/Levison [wie Anm. 59], 481,10-12; Übersetzung von W. Giesebrecht): in unius horae spatio [...] octaginta homines ad terram conruisse et spiritum exalasse. Sed non distitit sacerdos dandus praedicare populo, ne ab oratione cessarent. Vgl. Paul. Diac. Hist. Lang. 3,24 (ed. Waitz [wie Anm. 59], 105,7); Joh. Diac. Vita Greg. 1,43 (PL 75, 81A).

67 Gleichwohl zeitigte die Prozession auch im Hinblick auf die Pest den erhofften Erfolg: Obwohl die Seuche in Italien keinesfalls eingedämmt war und es immer wieder zu erneuten Ausbrüchen kam, galt sie nach Gregors Maßnahme als besiegt. Schon bald erhielt das Ereignis legendäre Züge: Der Erzengel Michael soll während der Prozession über der später nach ihm benannten Engelsburg erschienen sein und, um das Ende der Epidemie anzukündigen, sein blutiges Schwert in die Scheide gesteckt haben. Gregors erfolgreiche Pestprozession jedenfalls war im Mittelalter ein vielbeschworenes Ereignis. Die Prozession selbst entwickelte sich noch unter Gregors Pontifikat zu einer jährlichen Institution. Vgl. im einzelnen dazu Meier, Von Prokop zu Gregor von Tours (wie Anm. 60), $38 \mathrm{f}$.

68 Dagens, Fin des temps (wie Anm. 55), 280-284; McNally, Gregory the Great (wie Anm. 55), 18 f., mit Hinweis auf Greg. hom. in Hiezech. 2,6,22; 24 (M. Adriaen/V. Recchia/E. Gandolfo [Ed./Übers.], Sancti Gregorii Magni Homiliae in Hiezechihelem. Liber Secundus - San Gregorio Magno, Omelie su Ezechiele. Libro Secondo. Rom 1993, $170-172,174)$ aus dem Jahr 593, wo die traurige Lage Roms als symptomatisch für den endzeitlichen Zustand der Welt gedeutet wird (vgl. etwa ebenda 24 [a.a.O., 174]: Haec autem quae de Romanae urbis contritione dicimus, in cunctis facta mundi civitatibus scimus. [...] Despiciamus ergo ex toto animo hoc praesens saeculum vel exstinctum; finiamus mundi desideria saltem cum mundi fine); Dagens, Fin des temps, 273. Zum desolaten Zustand Roms und der Welt aus Gregors Sicht vgl. etwa Greg. Dial. 3,38 (edd. de Vogüé/Antin [wie Anm. 59], 428-432); hom. in Evang. 1,17,16 (M. Fiedrowicz [Ed./Übers.], Homiliae in Evangelia - Evangelienhomilien, I [Fontes Christiani, 28/1]. Freiburg/Basel/ Wien 1997, 296-298); hom. in Evang. 2,28,3 (M. Fiedrowicz [Ed./Übers.], Homiliae 
Von all dem sehen wir, wie es zum Teil tatsächlich schon eingetreten ist, von anderem fürchten wir, daß es in naher Zukunft hereinbrechen wird. Denn daß sich Volk gegen Volk erhebt und deren Drangsal die Erde heimsucht, nehmen wir in unseren Zeiten schon mehr wahr, als daß wir es in Büchern lesen. Ihr wißt, wie häufig wir schon von anderen Gegenden vernahmen, daß ein Erdbeben zahllose Städte einstürzen läßt. Unaufhörlich müssen wir Pestepidemien erdulden. Zwar sehen wir bislang noch keinerlei Zeichen an Sonne, Mond und Sternen, doch daß dies nicht mehr allzu weit entfernt ist, können wir aus klimatischen Veränderungen schließen. Immerhin haben wir, schon bevor Italien dem heidnischen Schwert ausgeliefert wurde, am Himmel feurige Schlachtreihen erblickt, sogar funkelndes Blut, welches später als das der Menschheit vergossen wurde. Ein außergewöhnliches Aufbrausen des Meeres und der Wogen ist bislang nicht eingetreten. Da sich aber viel Angekündigtes schon erfüllt hat, besteht kein Zweifel, daß auch das Wenige, das noch aussteht, folgt, bietet doch das Eintreten der vergangenen Ereignisse die Gewähr für das noch Kommende.

Minutiös werden hier die einzelnen Endzeitzeichen der Lukas-Prophezeiung durchgearbeitet und auf aktuelle Zeiterfahrungen bezogen, so daß tatsächlich niemand mehr bezweifeln konnte: Das Ende der Welt war gekommen. Um diese Schlußfolgerung noch zusätzlich zu illustrieren, greift der gelehrte Bischof sogar auf den traditionellen Topos vom Greisenalter der Welt zurück: ${ }^{70}$

in Evangelia - Evangelienhomilien, II [Fontes Christiani, 28/2]. Freiburg/Basel/Wien 1998, 524-526); hom. in Hiezech. 1,9,9 (M. Adriaen/V. Recchia/E. Gandolfo [Ed./ Übers.], Sancti Gregorii Magni Homiliae in Hiezechihelem. Liber Primus - San Gregorio Magno, Omelie su Ezechiele. Libro Primo. Rom 1992, 274); epist. 3,29; 3,61 (Ed. Norberg [wie Anm. 59], 174 f., 209-211); 5,37 (a.a.O., 309,53-58): Ecce cuncta in Europae partibus barbarorum iuri sunt tradita, destructae urbes, eversa castra, depopulatae provinciae; nullus terram cultor inhabitat; saeviunt et dominantur cotidie in nece fidelium cultores idolorum: et tamen sacerdotes, qui in pavimento et cinere flentes iacere debuerunt, vanitatis sibi nomina expetunt et novis ac profanis vocabulis gloriantur; 11,37 (S. Gregorii Magni Registrum epistularum, II, ed. D. Norberg [CCSL 140A]. Tournhout 1982, 929-932); mor. 21,22,35 (M. Adriaen [Ed.], S. Gregorii Magni moralia in Iob libri XIXXII [CCSL 143A]. Turnhout 1979, 1090,1-1091,34; PL 76, 210B-211A).

69 Greg. hom. in Evang. 1,1,1 (ed. Fiedrowicz [wie Anm. 68], 52): Ex quibus profecto omnibus alia iam facta cernimus, alia e proxima ventura formidamus. Nam gentem super gentem exsurgere, earumque pressuram terris insistere, plus iam in nostris temporibus cernimus, quam in codicibus legimus. Quod terraemotus urbes innumeras subruat, ex aliis mundi partibus scitis quam frequenter audivimus. Pestilentias sine cessatione patimus. Signa vero in sole et luna et stellis adhuc aperte minime videmus: sed quia et haec non longe sint, ex ipsa iam aeris immutatione colligimus. Quamvis priusquam Italia gentili gladio ferienda traditur, igneas in coelo acies vidimus, ipsum qui postea humani generis fusus est, sanguinem corruscantem. Confusio autem maris et fluctuum necdum nova exorta est. Sed cum multa praenuntiata iam completa sint, dubium non est, quin sequantur etiam pauca quae restant: quia sequentium rerum certitudo est praeteritarum exhibitio; dazu siehe Lauras, Le commentaire de Lc. 21,25-33, Studia Patristica 7 (1966) 503-515. Vgl. auch Greg. hom. in Evang. 2,35,1-3 (ed. Fiedrowicz [wie Anm. 68], 684-692); Dial. 3,38 (edd. de Vogüél Antin [wie Anm. 59], 428-432).

70 Greg. hom. in Evang. 1,1,5 (ed. Fiedrowicz [wie Anm. 68], 58-60): Ecce, fratres mei, iam cernimus, quod audiebamus. Novis quotidie et crebrescentibus malis mundus urgetur. Ex illa 
Seht, meine Brüder, schon schauen wir, was wir gehört haben. Täglich wird die Welt von neuen und stets größeren Übeln bedrängt. Ihr seht, wie wenige aus dem zahlreichen Volk übriggeblieben sind; dennoch bedrängen uns noch täglich Heimsuchungen, brechen plötzliche Unglücksfälle herein, treffen uns neue und unvorhergesehene Katastrophen. Wie nämlich in der Jugend der Körper voller Kraft ist, die Brust stark und gesund, der Nacken fest, die Bronchien voll, jedoch im Greisenalter die Gestalt gebeugt ist, der Nacken sich kraftlos neigt, häufige Atemnot die Brust beklemmt, die Kraft nachläßt, die Worte des Sprechenden von Kurzatmigkeit unterbrochen werden [...], ebenso stand die Welt in früheren Jahren sozusagen voller Jugendkraft, war stark genug, daß sich die Menschheit fortpflanzte, war voll blühenden Lebens und durch allseitigen Überfluß wohlauf. Nun jedoch wird sie durch ihr Greisenalter niedergedrückt und sozusagen durch zunehmende Beschwerden zum nahen Tod gedrängt.

All dies mündet - ähnlich wie die Predigt anläßlich der Pestprozession - in den eindringlichen Aufruf zur Buße, um doch noch vor Ablauf der verbleibenden Frist Erlösung zu erfahren: ${ }^{71}$

Daher gilt es zu bedenken, daß die gegenwärtigen Drangsale von jener letzten Drangsal so verschieden sind wie die Gestalt eines Herolds von der Macht eines Richters. Geliebte Brüder, richtet also eure Aufmerksamkeit auf jenen Tag, bessert euer Leben, ändert euren Lebenswandel, überwindet mit Widerstand die versucherischen Übel, die begangenen aber ahndet mit Tränen. Der Ankunft des ewigen

plebe innumera quanti remanseritis, aspicitis; et tamen adhuc quotidie flagella urgent, repentini casus opprimunt, novae nos et improvisae clades affligunt. Sicut enim in iuventute viget corpus, forte et incolume manet pectus, torosa cervix, plena sunt bronchia; in annis autem senilibus statura curvatur, cervix exsiccata deponitur, frequentibus suspiriis pectus urgetur, virtus deficit, loquentis verba anhelitus interdicit; [...] ita mundus in annis prioribus velut in iuventute viguit, ad propagandam humani generis prolem robustus fuit, salute corporum viridis, opulentia rerum pinguis; at nunc ipsa sua senectute deprimitur, et quasi ad vicinam mortem molestiis crescentibus urgetur. Vgl. auch Greg. hom. in Evang. 1,1,1 (ed. Fiedrowicz [wie Anm. 68], 50). Zum Topos des mundus senescens siehe Demandt, Metaphern (wie Anm. 44), 37-45. Gregor entwickelt an anderer Stelle, in einer wohl Anfang 591 gehaltenen Predigt über das Gleichnis von den Arbeitern im Weinberg (Mt 20), das Schema der Altersstufen der Welt weiter und deutet dabei die Phase von der Ankunft des Herrn bis zum Ende der Welt (ab adventu Domini usque ad finem mundi) als elfte Stunde und Zeit der Altersschwäche bzw. des hohen Alters (undecima vero hora ea est, quae decrepita vel veterana dicitur), vgl. Greg. hom. in Evang. 1,19,1-2 (ed. Fiedrowicz [wie Anm. 68] , 320-324). - Zum Schema der sechs Zeitalter der Welt bei Gregor siehe Markus, Gregory the Great (wie Anm. 54), 56. Allgemein dazu P. Siniscalco, Le età del mondo in Gregorio Magno, in: Fontaine u.a. (Hgg.), Grégorie le Grand (wie Anm. 55), 377-387.

71 Greg. hom. in Evang. 1,1,6 (ed. Fiedrowicz [wie Anm. 68], 62): Unde et considerare necesse est, quia ab illa tribulatione ultima tantum sunt istae tribulationes dissimiles, quantum a potentia iudicis persona praeconis distat. Illum ergo diem, fratres carissimi, tota intentione cogitate, vitam corrigite, mores mutate, mala tentantia resistendo vincite, perpetrata autem fletibus punite. Adventum namque aeterni iudicis tanto securiores quandoque videbitis, quanto nunc districtionem illius timendo praevenitis. 
Richters werdet ihr einmal um so sicherer entgegensehen, je mehr ihr jetzt seiner

Strenge durch Furcht zuvorkommt.

Gregor dürfte mit seinen bewegenden Worten das ausgesprochen haben, was viele seiner Zeitgenossen umtrieb. Als Bischof von Rom kann er kaum lediglich eigene übersteigerte Individualerwartungen in seinen Predigten und Schriften verbreitet haben, sondern war gezwungen, gerade auf die Ängste und Hoffnungen der Gläubigen einzugehen. Man wird daher nicht fehlgehen, ihn als Sprachrohr verbreiteter Haltungen anzusehen. Zugleich wird sein Einfluß als Papst aber auch mit dazu beigetragen haben, daß entsprechende Befürchtungen - auch außerhalb Italiens - noch weiteren Nährboden erhielten. Denn der Bischof von Rom stellte sich ganz in den Dienst der Eschatologie und trat als entschiedener Verkünder des baldigen Weltendes auf. Welthistorische Bedeutung hat er dadurch erlangt, daß er u.a. mit Blick auf den in Kürze anbrechenden jüngsten Tag ein groß angelegtes Programm zur Heidenmission eingeleitet hat (vor allem der Angelsachsen in Britannien), um möglichst vielen Menschen die Gelegenheit zu geben, die noch verbleibende Zeit zur Bekehrung und Buße zu nutzen und so den ewigen Frieden zu finden. ${ }^{72}$ Nur ein asketischheiligmäßiges Leben konnte nach Gregors Überzeugung jetzt noch Rettung garantieren, und insbesondere seine 4 Bücher Dialogi sollten demonstrieren, daß diese Heiligkeit für alle erreichbar war. ${ }^{73}$

Vor allem die aktuellen Mißstände der eigenen Zeit, insbesondere die politischen Unsicherheiten in Italien nach dem Langobardeneinfall, die Verwüstungen und der Hunger auf der Apenninhalbinsel infolge der desaströsen ostgotisch-oströmischen Kriege und diverse Naturkatastrophen scheinen Gregor und wohl auch viele Zeitgenossen dazu geführt zu haben, ihre Ängste und Hoffnungen in eschatologischen Kategorien zu verarbeiten; der Zusammenhang zwischen der Wahrnehmung eines universalen Niedergangs und eschatologischen Spekulationen ist bei Gregor jedenfalls stets präsent. Hingegen waren Persönlichkeiten wie Cassiodor oder Isidor von Sevilla, die vor und nach Gregor

72 Greg. epist. 11,37 (ed. Norberg [wie Anm. 68], bes. 931,43-50). Vgl. Dagens, Fin des temps (wie Anm. 55), $276 \mathrm{f}$; H. Chadwick, Gregory the Great and the Mission to the Anglo-Saxons, in: Gregorio Magno e il suo tempo. XIX incontro di studiosi dell'antichità cristiana in collaborazione con l'École Française de Rome. Roma, 9-12 maggio 1990, I: Studi storici. Rom 1991, 199-212, hier 206; Markus, Gregory the Great (wie Anm. 54), 54, 59 (,All Gregory's eschatological purple passages serve this end: to proclaim an ascetic Christian morality of renunciation“), 177-187; Simonetti, Gregorio Magno (wie Anm. 55), 314, 319; Prinz, Von Konstantin zu Karl dem Grossen (wie Anm. 4), 52, 335.

73 McNally, Gregory the Great (wie Anm. 55), 14; Markus, Gregory the Great (wie Anm. 54), 66. 
jeweils in Phasen größerer Sicherheit lebten, auf entsprechende Deutungskategorien nicht angewiesen. ${ }^{74}$

Im späten 6. Jahrhundert jedoch war die Angst vor dem Ende im Westen ein Phänomen, dem man immer wieder begegnet. Der irische Missionar Columban d. J. († 616) etwa äußert ähnliche Gedanken, ${ }^{75}$ und vor allem der fränkische Historiker Gregor von Tours ( $†$ 594) bietet in dieser Hinsicht reichhaltiges Material. ${ }^{76}$ Falsche Wundermänner und Propheten, so berichtet er, durchzogen überall die Lande (per totas Gallias emerserunt) ${ }^{77}$ und gaben Anlaß zu endzeitlichen Spekulationen - denn ihre Ankunft hatte schon der Evangelist Matthäus für die letzten Zeiten angekündigt (Mt 24,24), und auf diesen Zusammenhang macht der Historiker denn auch explizit aufmerksam: ${ }^{78}$

So gibt es viele, die nicht ablassen, mit solchen Verführungskünsten das unwissende Volk in Irrtum zu setzen; von ihnen gilt, wie ich meine, was der Herr im Evangelium über die jüngsten Zeiten sagt: „Es werden Pseudochristus und falsche Propheten aufstehen und große Zeichen und Wunder tun, daß verführet werden in den Irrtum auch die Auserwählten."

Sowie an anderer Stelle: ${ }^{79}$

74 Vgl. Markus, Gregory the Great (wie Anm. 54), 54.

75 Columbanus, Carmen de mundi transitu (G. S. M. Walker [Ed.], Sancti Columbani Opera. Dublin 1957, 182-184); epist 5,4 (ed. Walker, 40): mundus iam declinat; 5,7 (ed. Walker, 42): Dominus appropinquat, et prope iam in fine consistimus inter tempora periculosa; serm 3,1 (ed. Walker, 72): mundus enim transibit et cottidie transit et rotatur ad finem. Dazu McNally, Gregory the Great (wie Anm. 55), $13 \mathrm{f}$.

76 Allgemein dazu G. de Nie, Roses in January: A Neglected Dimension in Gregory of Tour' Historiae, Journal of Medieval History 5 (1979) 259-289; dies., Views from a Many-Windowed Tower. Studies of Imagination in the Works of Gregory of Tours. Amsterdam 1987, 46 ff. Vgl. allerdings Goffart, Narrators (wie Anm. 38), 187, der die Bedeutung entsprechender Passagen - sicherlich zu unrecht - nicht allzu hoch veranschlagt: "Casual allusions aside, the subject returns only in the books IX-X, in the limited context of false prophets and miracle workers". Eine solche Sichtweise verkennt aber den grundsätzlich eschatologisch ausgerichteten, auf das endzeitlich konnotierte Buch 10 hin angelegten Aufbau des Gesamtwerks, den Heinzelmann, Gregor von Tours (wie Anm. 65), 69 ff., klar herausgearbeitet hat.

77 Greg. Tur. Hist. 10,25 (edd. Krusch/Levison [wie Anm. 59], 519,9).

78 Greg. Tur. Hist. 9,6 (edd. Krusch/Levison [wie Anm. 59], 420,2-6; Übersetzung nach W. Giesebrecht): Multi enim sunt, qui, has seductiones exercentes, populum rusticum in errore ponere non desistunt, de quibus, ut opinor, et Dominus in euangelio ait, consurgere in novissimis temporibus pseudochristus et pseudoprophetas, qui, dantes signa et prodigia, etiam electos in errore inducant.

79 Greg. Tur. 10,25 (edd. Krusch/Levison [wie Anm. 59], 517,16-20; Übersetzung von W. Giesebrecht): At in Galliis Masiliensim Provintiam morbus saepe nominatus invasit. Andecavos, Namneticos atque Cenomanicos valida famis oppressit. Initia sunt enim haec dolorum iuxta illud quod Dominus ait in euangelio: Erunt pestilentiae et fames et terrae motus per loca; et exurgent pseudochristi et pseudoprophetae et dabunt signa et prodigia in caelo, ita ut electos in errore mittant. 
In Gallien suchte die oftgenannte Seuche die Provence von Marseille heim. Die Gebiete von Angers, Nantes und Le Mans litten unter großer Hungersnot. Damit hebt sich allererst die Not an, wie der Herr im Evangelium sagt: „Es werden sein Pestilenz und teuere Zeit und Erdbeben hin und wieder, und es werden sich erheben falsche Christi und falsche Propheten, die Zeichen und Wunder tun, daß sie auch die Auserwählten verführen."

Auch in einem Brief der Hl. Radegunde, den der Historiker zitiert, wird auf das nahe Weltgericht verwiesen ${ }^{80}$ - zum Ende des Geschichtswerks häufen sich ohnehin entsprechende Passagen und münden in das abschließende 10. Buch, das eine eigene Einheit darstellt, insofern es einen hocheschatologischen Charakter besitzt. ${ }^{81}$ Es setzt ein mit der in apokalyptischen Farben ausgemalten Beschreibung der desolaten Lage Roms während der Tiberflut und Pest 589/90, diskutiert mit Erdbeben, Sonnenfinsternis, Unwettern, Seuchen, Krieg und dem Erscheinen eines (Ps.-)Antichrist endzeitliche Vorzeichen ${ }^{82}$ und schließt mit einer vollständigen Liste der Bischöfe von Tours als Repräsentanten der Kontinuität der Kirche ${ }^{83}$ sowie einer Kalkulation der Weltjahre von der Schöpfung bis zum Jahr 594.

Diese Berechnung folgt explizit (wenngleich nicht ganz exakt) der Chronologie des Eusebios/Hieronymus ${ }^{84}$ und setzt das Jahr 594 n. Chr. mit dem Weltjahr 5792 gleich. Die Aufstellung bildet den Abschluß eines Ringens mit Fragen nach dem Zeitpunkt des Weltendes, das Gregors gesamtes Geschichtswerk durchzieht. Schon am Ende des 4. Buches, anläßlich des Todes Sigiberts I. im Jahre 575, hatte Gregor eine ähnliche Kalkulation der Weltjahre vorgelegt. ${ }^{85}$ Noch bedeutsamer aber ist, daß der Autor bereits in seiner Praefatio als wich-

80 Greg. Tur. Hist. 9,42 (edd. Krusch/Levison [wie Anm. 59], 471,5 f.): Sed quoniam incerta sunt humanae conditionis momenta vel tempora, quippe mundo in fine currente [...].

81 Dazu siehe im einzelnen Heinzelmann, Gregor von Tours (wie Anm. 65), $69 \mathrm{ff}$.

82 Greg. Tur. Hist. 10,23-25 (edd. Krusch/Levison [wie Anm. 59], 514,20-519,13); dazu Heinzelmann, Gregor von Tours (wie Anm. 65), $73 \mathrm{f}$.

83 Heinzelmann, Gregor von Tours (wie Anm. 65), 70, weist darauf hin, daß in Buch 10 die römische Kirche, repräsentiert durch Papst Gregor, ein besonderes Gewicht innerhalb der Darstellung erhält. Er führt dies darauf zurück, daß in diesem abschließenden Buch des Geschichtswerks das Thema „einer eschatologischen, nicht institutionellen Kirche, bestehend aus der ,Gemeinschaft der Heiligen' und repräsentiert in der Gestalt von Bischofsgremien“ in besonderem Maße erörtert werde. Dies würde einmal mehr auf den hocheschatologischen Charakter von Buch 10 verweisen.

84 Vgl. Greg. Tur. Hist. 1 praef. (edd. Krusch/Levison [wie Anm. 59], 5,11-13): De subpotatione vero huius mundi evidenter chronicae Eusebii Caesariensis episcopi ac Hieronimi presbiteri prolocuntur et rationem de omni annorum serie pandunt. Dazu van den Brincken, Weltchronistik (wie Anm. 18), 98: „Er folgt in den Zahlenangaben Hieronymus, verfährt dabei jedoch mit recht fragwürdiger Genauigkeit“; A. H. B. Breukelaar, Historiography and Episcopal Authority in Sixth-Century Gaul. The Histories of Gregory of Tours Interpreted in Their Historical Context. Göttingen 1994, 304.

85 Greg. Tur. Hist. 4,51 (edd. Krusch/Levison [wie Anm. 59], 189,15-190,8). 
tigen Zweck seines Werkes angibt: „Auch habe ich es wegen der Berechnung der Jahre für gut gehalten, vom Anfang der Welt in dem ersten Buch zu beginnen $[\ldots]$ “ ${ }^{86}$ Und noch deutlicher wird er dann in der Einleitung zum 1. Buch: „Auch habe ich beschlossen um deretwillen, die da banget vor dem herannahenden Weltende, durch eine Berechnung der verflossenen Jahre nach den Chroniken und Geschichten genau darzutun, wie viele Jahre vom Beginn der Welt bereits verstrichen sind“". ${ }^{87}$

Es ist evident, daß Gregor mit seinem Geschichtswerk auf konkrete Endzeitängste einging, die offenbar - wie der Erfolg der Pseudopropheten zeigt weit verbreitet waren. ${ }^{88} \mathrm{Ob}$ der Historiker selbst sich diese Ängste zu eigen gemacht hat, ist in der Forschung allerdings umstritten. ${ }^{89}$ Zum einen impliziert die Übernahme des eusebianischen Modells die Überzeugung, daß die 6000 Jahre noch nicht abgelaufen seien, und verweist unmißverständlich in die Zeit um 800; auch Gregors Aufruf an die Nachwelt, seine Schriften in Zukunft mit der gebotenen Ehrfurcht zu behandeln, ${ }^{90}$ spricht für eine längerfristige Perspektive. Andererseits aber hebt der Historiker selbst im Kontext seines

86 Greg. Tur. Hist. praef. (edd. Krusch/Levison [wie Anm. 59], 1,15 f.; Übersetzung nach W. Giesebrecht): Libuit etiam animo, ut pRo SUPPOTATIONE ANNORUM ab ipso mundi principio libri primi poniretur initium [...].

87 Greg. Tur. Hist. 1 praef. (edd. Krusch/Levison [wie Anm. 59], 3,15-17; Übersetzung nach W. Giesebrecht): Illud etiam placuit propter eos, qui adpropinquantem finem mundi disperant, ut, collectam per chronicas vel historias anteriorum annorum summam, explanitur aperte, quanti ab exordio mundi sint anni.

88 Vgl. in diesem Sinne auch B. Croke, Latin Historiography and the Barbarian Kingdoms, in: Marasco, Greek and Roman Historiography (wie Anm. 28), 381: „Indeed, it may be that the whole History was influenced by Gregory's need to deal with local apocalyptic concerns".

89 Vgl. dazu etwa van den Brincken, Weltchronistik (wie Anm. 18), 97: „Er will [...] doch wohl zum Ausdruck bringen, daß das Jahr 6000 noch weit entfernt sei“; de Nie, Roses (wie Anm. 76), passim, bes. 277 ff.; dies., Views (wie Anm. 78), 46-57, 66-68 (jeweils mit der Annahme, im Verlauf von Gregors Werk kristallisiere sich eine zunehmende Endzeiterwartung heraus); Goffart, Narrators (wie Anm. 38), 187: „[...] Gregory is in fact no more inclined than most Christian historians before and after him to search the horizon for signs of the End. [...] There is little reason to infer that Gregory, when nearing the close of the Histories, became convinced that the Second Coming was at hand“; Breukelaar, Historiography (wie Anm. 84), $304 \mathrm{f} .:$ „Whereas he in the late $580 \mathrm{~s}$ interpreted various signs as forebodings of the Last Day, now [in cap. 4,51] his computation teaches that, if the world supposedly comes to an end in the year 6000 after Creation, this was still a comforting number of generations away. By the time he was concluding the Histories Gregory apparently assumed a longer span of time between the present moment and the Last Day"; Heinzelmann, Gregor von Tours (wie Anm. 65), 71: „In welchem Maß unser Autor selbst an ein unmittelbar bevorstehendes Ende der Welt glaubte, läßt sich trotz mehrfacher Aussagen zu diesem Thema nicht endgültig klären“. Zur Diskussion dieses Problems in der Forschung siehe ebenda 205 mit Anm. 81.

90 Greg. Tur. Hist. 10,31 (edd. Krusch/Levison [wie Anm. 59], 536,2 ff.). 
einleitenden Glaubensbekenntnisses hervor, daß vor dem Ende der Welt zunächst der Antichrist erscheinen müsse, doch sei bereits im Evangelium zu lesen, daß man dafür weder den Tag noch die Stunde wisse (dies wäre wieder eher im Sinne Augustins). ${ }^{91}$ Damit jedoch weicht er die konkrete Zeitangabe seiner Jahresberechnungen implizit bereits zu Beginn seines Werkes auf. Und schließlich könnte die apokalyptische Stimmung im 10. Buch sogar dafür sprechen, daß Gregor doch möglicherweise vom allgemeinen Endzeitfieber nicht ganz unberührt geblieben ist. ${ }^{92}$ Vordergründig wollte er also offenbar - wie so viele Chronographen vor ihm - seine Zeitgenossen davon überzeugen, daß die Parusie noch nicht bevorsteht. Ob er sich dabei aber wirklich so sicher war, ist schwer zu entscheiden.

Trotz der Unsicherheiten hinsichtlich der Deutung des gregorianischen Geschichtswerks kann aber grundsätzlich festgehalten werden: Im späteren 6. Jahrhundert haben offenbar in Gallien und Italien konkrete Endzeitängste um sich gegriffen, ganz ähnlich wie um $500 \mathrm{im}$ Osten. Anders als damals aber dürften die Ursachen für die Naherwartungen im Westen weniger auf die chronologischen Modelle zurückzuführen sein, die noch um 500 den Osten fest im Griff hatten; vielmehr scheinen nunmehr vor allem unsichere politische Verhältnisse zusammen mit Seuchen und anderen Naturkatastrophen einen entscheidenden Faktor dargestellt zu haben. ${ }^{93}$ Auch für das spätere 6. Jahrhundert kann jedenfalls festgehalten werden, daß das eschatologische Denken in Ost und West wiederum ganz unterschiedliche Signaturen aufweist: Konkrete Endzeitängste im Westen - Diskussionen über ,neue Parusietermine angesichts enttäuschter Endzeiterwartungen im Osten. In einem so zentralen gemeinsamen Anliegen wie der christlichen Eschatologie und Apokalyptik gingen Osten und Westen im 6. Jahrhundert also vollkommen unterschiedliche Wege. Man dachte und redete aneinander vorbei. Daß man den Sachverhalt tatsächlich derart deutlich fassen muß, soll der letzte Teil meines Beitrages begründen, die Analyse eines Briefes eines Trierer Bischofs an einen oströmischen Kaiser. Dieses Schreiben vermag anschaulich zu illustrieren, welche Welten bereits um die Mitte des 6. Jahrhunderts die westliche und die östliche Sphäre voneinander trennten.

91 Greg. Tur. Hist. 1 praef. (edd. Krusch/Levison [wie Anm. 59], 5,3 f.).

$92 \mathrm{Zu}$ diesem Konflikt vgl. auch Landes, Apocalyptic Expectations (wie Anm. 19), 166.

$93 \mathrm{Zu}$ Gregor von Tours vgl. in diesem Sinne auch van den Brincken, Weltchronistik (wie Anm. 18), 97: „Offenbar flackert hier die Vorstellung von einer 6000-jährigen Weltdauer angesichts der inneren Unruhen im Frankenreich wieder auf.“ 
IV.

Im 6. Jahrhundert verzeichnete das fränkische Trier noch einmal einen beträchtlichen Aufschwung. ${ }^{94}$ Dies war vor allem der schillernden Persönlichkeit des Nicetius zu verdanken, der im Jahr 525 auf Drängen Theuderichs I. (511533) zum Bischof von Trier gewählt worden war. ${ }^{95}$ Nicetius übte während seines gesamten, wohl bis 566 währenden Episkopats erheblichen Einfluß auf die merowingischen Herrscher aus und scheute auch nicht vor Konflikten mit ihnen zurück. ${ }^{96}$ Er verfügte über weitreichende Kontakte, u.a. zu Venantius Fortunatus, ${ }^{97}$ und initiierte in Trier ein umfangreiches Bauprogramm. ${ }^{98}$ Nicht nur deshalb wurde er bereits zu Lebzeiten heiligmäßig verehrt, und es verwundert insofern auch nicht, daß Gregor von Tours ihm neben verschiedenen Erwähnungen in seinen Werken sogar eine eigene Vita gewidmet hat. ${ }^{99}$ Auch als Kirchenpolitiker war Nicetius aktiv: Für mindestens vier gallische Synoden ist seine Teilnahme belegt. ${ }^{100}$ Diese regionale Anerkennung scheint ihn dazu verleitet zu haben, seine Bedeutung doch ein wenig zu überschätzen.

Aus seiner Korrespondenz sind zwei Briefe überliefert, von denen einer an den oströmischen Kaiser Justinian gerichtet ist. ${ }^{101}$ Die Datierung des Schreibens ist unsicher; die Anspielung auf das hohe Alter Justinians, die vereinzelt als Indiz

94 Vgl. dazu E. Ewig, Trier im Merowingerreich. Civitas, Stadt, Bistum. Trier 1954, bes. $88 \mathrm{ff}$; H. H. Anton, Die Trierer Kirche und das nördliche Gallien in spätrömischer und fränkischer Zeit, in: H. Atsma (Hg.), La Neustrie. Les pays au nord de la Loire de 650 à 850. Colloque historique international, II. Sigmaringen 1989, 53-73.

95 H. A. Pohlsander, A Call to Repentance: Bishop Nicetius of Trier to the Emperor Justinian, Byz 70 (2000) 456-473, bes. 459. Zu Nicetius siehe auch Ewig, Trier (wie Anm. 94), 97 ff.; Chr. Schulze im Lexikon der antiken christlichen Literatur, hg. von S. Döpp/W. Geerlings. Freiburg/Basel/Wien ${ }^{3} 2002$, 519 (s.v. Nicetius von Trier), mit weiterer Literatur; bes. N. Gauthier, Lévangélisation des pays de la Moselle. La province romaine de Première Belgique entre Antiquité et Moyen Age (III - VIII ${ }^{e}$ ). Paris 1980, $172-189$.

96 Pohlsander, Call to Repentance (wie Anm. 95), 459.

97 Venant. Fort. carm. 3,11; 3,12 (M. Reydellet [Ed.], Venance Fortunat, Poèmes, I: Livres I-IV. Paris 2002, 106-109).

98 Pohlsander, Call to Repentance (wie Anm. 95), 459 mit Anm. 24.

99 Greg. Tur. Liber vitae patr. 17 (W. Arndt/B. Krusch [Ed.], Gregorii Turonensis opera, II: Miracula et opera minora. MGH Scriptores rerum I/2. Hannover 1885, 727-733); Hist. 10,29 (edd. Krusch/Levison [wie Anm. 59], 522-524); Glor. confess. 92 (edd. Arndt/Krusch, 807,5-13). Dazu siehe Pohlsander, Call to Repentance (wie Anm. 95), 457.

100 Clermont (525), Fünftes Konzil von Orléans (549), Toul (ca. 550), zweites Konzil von Paris (552); Belege bei Pohlsander, Call to Repentance (wie Anm. 95), 460.

101 Edition: W. Gundlach, Epistolae Austrasicae. Berlin ${ }^{2} 1957$ (MGH Epist. III [Merowingici et Karolini Aevi I]), 118-119 (Nr. 7) = W. Gundlach, Epistulae Austrasicae. Turnhout 1962 (CC SL117), 416-418 (Nr. 7); der Text auch bei Pohlsander, Call to Repentance (wie Anm. 95), 464-465. 
für eine Spätdatierung herangezogen wird, ist angesichts der Tatsache, daß Justinian erst im Alter von ca. 83 Jahren starb und somit sehr lange sehr alt war, nur wenig aussagekräftig. ${ }^{102}$ Möglicherweise stehen im Hintergrund des Briefes die Verurteilungen des Eutyches und Nestorios auf dem Konzil von Orléans $549,{ }^{103}$ so daß eine Datierung um 550 angenommen werden kann. ${ }^{104}$ Für unsere Zwecke ist ohnehin weniger der Zeitpunkt der Abfassung entscheidend als die Frage, wie Nicetius gegenüber Justinian mit eschatologisch-apokalyptischen Aspekten und über sie kommuniziert.

Der Brief ist gekennzeichnet von einer akuten und vehement artikulierten Naherwartung. Gleich zu Beginn weist Nicetius darauf hin, daß der jüngste Tag unmittelbar bevorstehe. ${ }^{105}$ Diese Endzeiterwartung dient im folgenden als Hintergrund, um den oströmischen Kaiser zur Buße aufzurufen; dabei scheut Nicetius auch nicht vor massiven Beleidigungen des Kaisers zurück, die nicht nur in der zumindest ungewöhnlichen Anrede dulcis noster Iustiniane zum Ausdruck kommen, ${ }^{106}$ sondern vor allem in der Anspielung auf dessen Rolle im endzeitlichen Prozeß ${ }^{107}$ und in der Behauptung, er sei der Sohn des Teufels und Feind der Gerechtigkeit. ${ }^{108}$

Der eigentliche Vorwurf gegenüber dem Kaiser richtet sich darauf, daß er glaube, Christus sei lediglich ein Mensch gewesen, ${ }^{109}$ ferner daß er Bischöfe habe verfolgen, foltern und töten lassen ${ }^{110}$ und daß er die Lehren des Nestorios und des Eutyches propagiere. ${ }^{111}$ Aufgrund des nahenden Endes solle er all diesen Verfehlungen abschwören und möglichst rasch Buße tun, um der ewigen Verdammnis zu entgehen: Festina, festina, sed protinus. Nam si te sic ultimus dies invenerit, qualis nunc hodie appares, descenderis in inferiora terrae, et ad partes

102 Nicet. epist. ad Iust. 5 (ed. Gundlach [wie Anm. 101], 119,8 f.): in ultima aetate tua; dazu siehe Pohlsander, Call to Repentance (wie Anm. 95), 469.

103 Vgl. C. de Clercq (Ed.), Concilia Galliae A. 511 - A. 695 (CCSL 148A). Turnhout 1963, 148-149.

104 So Pohlsander, Call to Repentance (wie Anm. 95), 469. Ewig, Merowinger (wie Anm. 9), 23, setzt das Schreiben in die Zeit 550-553.

105 Nicet. epist. ad Iust. 1 (ed. Gundlach [wie Anm. 101], 118,17): In novissimis temporibus iam, ut sermo evangelicus praedixit, prospicimus et [...] finem, ut scribtura denuntiavit, venire sentimus.

106 Nicet. epist. ad Iust. 3 (ed. Gundlach [wie Anm. 101], 118,23 f.); vgl. ferner ebd., 5 (ed. Gundlach a.a.O., 119,2): dulcis et dulcis noster Iustiniane. Dazu Pohlsander, Call to Repentance (wie Anm. 95), 469. Für Ewig, Merowinger (wie Anm. 9) 23, Anm. 90, verrät die Anrede „zweifellos eine persönliche Empfindung“.

107 Vgl. Nicet. epist. ad Iust. 1-2 (ed. Gundlach [wie Anm. 101], 118,17-32).

108 Nicet. epist. ad Iust. 8 (ed. Gundlach [wie Anm. 101], 119,24 f.): Victus es et vinctus, sed inde, unde filius diabuli et inimicus iustitiae.

109 Nicet. epist. ad Iust. 3 (ed. Gundlach [wie Anm. 101], 118,24 f.): qui, ut Christum purum hominem fatearis, docuit?; 6 (ed. Gundlach a.a.O., 119,16): purum hominem fecisti.

110 Nicet. epist. ad Iust. 3; 4; 9 (ed. Gundlach [wie Anm. 101], 118,31 f.; 119,8 f.; 119,31).

111 Nicet. epist. ad Iust. 4; 8 (ed. Gundlach [wie Anm. 101], 118,32 f.; 119,27 f.). 
vulpium eris - „Eile, eile, und zwar vorwärts! Denn wenn dich der Jüngste Tag so vorfindet, wie du jetzt erscheinst, wirst du in die Tiefen der Erde hinabsteigen und zur Beute der Füchse werden" (vgl. Ps 63,10 f.). ${ }^{112}$

Dieser Brief ist ein ernüchterndes Zeugnis dafür, welch massive Unkenntnis der kirchenpolitischen Vorgänge im Osten im 6. Jahrhundert selbst bei einer einflußreichen und überregional vernetzten Persönlichkeit wie Nicetius vorgeherrscht hat. ${ }^{113}$ Nahezu alles, was der Bischof in diesem Brief artikuliert, ist falsch. Justinian hat natürlich niemals behauptet, Christus sei nur Mensch gewesen, sondern hat - im Gegenteil - derartige Verwandtschaft zu nestorianischen Ansichten aufweisende Positionen in aller Schärfe verurteilt. Selbst unter den härtesten Verfolgungswellen gegenüber miaphysitischen Bischöfen hat er keine Folterungen und Hinrichtungen befohlen, und der Vorwurf, Lehren des Nestorios und des Eutyches zu vertreten, ist schon deshalb völlig unhaltbar, weil deren Positionen derart entgegengesetzt waren, daß sie sich gegenseitig ausgeschlossen haben.

Entsprechend negativ fällt denn auch das Urteil der Forschung über den Brief des Nicetius aus, der im besten Fall als ausgesprochen undiplomatisch, uninformiert und unbeherrscht angesehen wird. ${ }^{114}$ Solche Urteile sollten aber beachten, daß man dieses Verdikt nicht über Nicetius als Einzelpersönlichkeit verhängen sollte, sondern daß seine Unkenntnis die Folge eines offenbar generellen Abbruchs der Kommunikation zwischen Ost und West darstellt. Dieser Sachverhalt manifestiert sich besonders deutlich in der Funktion der Eschatologie in Nicetius' Schreiben: Sie erscheint als reines Druckmittel zur Durchsetzung vollkommen absurder, auf Desinformation beruhender Forderungen. Nicetius kommuniziert nicht über Endzeiterwartungen, sondern mit ihrer Hilfe, ohne sich der Tatsache bewußt zu sein, daß diese Stoßrichtung ins Leere laufen mußte, weil die akuten Naherwartungen im Osten seit ca. Mitte des 6. Jahrhunderts keine besondere Rolle mehr gespielt haben. Die Artikulation end-

112 Nicet. epist. ad Iust. 7 (ed. Gundlach [wie Anm. 101], 119,19-21).

113 Nicetius selbst erwähnt einen Lactantius, der ihm möglicherweise Informationen aus dem Osten übermittelt haben könnte (Nicet. epist. ad Iust. 5 [ed. Gundlach (wie Anm. 101), 119,10]). Ewig, Merowinger (wie Anm. 9), 23, zufolge signalisiert der Brief eine weiterhin klare Verbundenheit selbst austrasischer Bischöfe des 6. Jh. mit dem Imperium; diese Interpretation wird allerdings von Anton, Trierer Kirche, 66, mit gutem Grund zurückgewiesen.

114 So Pohlsander, Call to Repentance (wie Anm. 95), 470 („very undiplomatic, ill-informed, and intemperate"); weitere Forschungsstimmen ebd., $468 \mathrm{f}$. Vgl. aus der neueren Literatur vor allem Anton, Trierer Kirche (wie Anm. 94), 65: „Die simplistische Theologie und die krasse Nichtkenntnis der theologischen Position von Konstantinopel verraten einen deutlichen Abstand zu Subtilität und Geistigkeit der Spätantike. Dieser Abstand wäre einem Autor Südgalliens kaum zuzutrauen; was man hier antrifft, sind Mentalität, Gedankenführung und Diktion eines Angehörigen der nördlichen, sich aus dem Bannkreis der Antike lösenden Zone.“ 
zeitlich-apokalyptischer Befürchtungen ist also Teil eines sinnlosen und erfolglosen Kommunikationsversuchs. Ob Justinian diesen Brief überhaupt persönlich gelesen hat, wissen wir nicht. Aber selbst wenn dies der Fall gewesen wäre, so hätte er seinerseits sicherlich überhaupt nicht verstanden, was der Bischof aus dem fernen Trier, der ihm Sympathien gegenüber Eutyches und Nestorios vorwarf, eigentlich von ihm wollte.

Nicetius ist kein Einzelfall. Auch Gregor von Tours zeigt sich in seinem groß angelegten und universalhistorisch konzipierten Geschichtswerk auffällig schlecht informiert über Vorgänge im oströmischen Reich, ${ }^{115}$ und Gregor d. Gr. verstand es lediglich durch geschickte Diplomatie und geschmeidige Formulierungen, die unterschiedlichen Sphären nicht ganz so entfernt erscheinen zu lassen; ${ }^{116}$ auch er versuchte im übrigen, dem oströmischen Kaiser das unmittelbar drohende Weltende auszumalen, um ihn zur Umkehr - in diesem Fall ganz konkret zur Rücknahme eines Gesetzes - zu bewegen. ${ }^{117}$ Im Osten sah dies nicht viel anders aus: Der sog. Frankenexkurs im Geschichtswerk des Agathias etwa zeigt deutlich, daß auch der oströmische Historiker nur sehr schemenhafte Vorstellungen von der Großmacht besaß, die immerhin weite Teile des ehemaligen Imperium Romanum kontrollierte. ${ }^{118}$

\section{V.}

Es stellt sich nun die Frage, inwieweit man das Feld der Eschatologie tatsächlich als repräsentativ für das Problem der Kommunikation zwischen Ost und West im 6. Jahrhundert ansehen kann und welche generalisierenden Rückschlüsse sich somit aus dem vorgestellten Befund ziehen lassen. Man wird hier sicherlich

115 Dies wurde in der Forschung verschiedentlich hervorgehoben, vgl. etwa Ewig, Merowinger (wie Anm. 9), 58; Croke, Latin Historiography (wie Anm. 88), 381. Demgegenüber betont allerdings Cameron, Byzantine Sources of Gregory of Tours (wie Anm. 9), daß Gregor immerhin vereinzelt auf solides Material aus dem Osten zurückgegriffen habe.

$116 \mathrm{Zu}$ den Beziehungen Gregors mit Byzanz ist noch immer die Untersuchung von Fischer, Gregor der Große und Byzanz (wie Anm. 58), 15 ff. grundlegend.

117 Vgl. Greg. epist. 3,61 (ed. Norberg [wie Anm. 59], bes. 210,49-62; aus dem Jahr 593). Bewirkt hat dies freilich nichts. Wir kennen zwar nicht die Antwort des Maurikios auf den Klagebrief des Papstes, doch im Jahr 597 sah sich Gregor endgültig gezwungen, seine eigene Interpretation des Gesetzes (das also nicht zurückgenommen wurde) zu formulieren und den Metropoliten zukommen zu lassen (epist. 8,10 [ed. Norberg [wie Anm. 68] , 527 f.]). Zu diesem Konflikt vgl. im einzelnen Fischer, Gregor der Große und Byzanz (wie Anm. 58), $57 \mathrm{ff}$.

118 Zum ,Frankenexkurs' des Agathias (hist. 1,2-4 [ed. Keydell (wie Anm. 49)], 11-15) siehe Av. Cameron, Agathias on the Early Merovingians, Annali della Scuola Normale Superiore di Pisa 37 (1968) 95-140; dies., Agathias. Oxford 1970, 50 f., 54, 120. 
sehr vorsichtig sein müssen. Andererseits ist aber auch festzuhalten, daß die Eschatologie nur ein Beispiel ist, an dem sich das fortschreitende Auseinanderdriften der ehemaligen Teile des Römischen Reiches illustrieren läßt - allerdings ein besonders eindringliches. Denn gerade dieser zentrale Bereich hätte doch eigentlich ein verbindendes Element unter christlichen Gesellschaften darstellen müssen - zumindest wäre dies zu erwarten gewesen. Auch auf anderen Feldern läßt sich die zunehmende Distanz von Ost und West nachweisen Peter Brown etwa hat dies am Beispiel der unterschiedlichen Konzeptionen des Heiligen getan. ${ }^{119}$

Unser Befund wirft jedenfalls eine Reihe grundsätzlicher Fragen auf, auf die ich zumindest hinweisen möchte: Zum einen wäre in einem nächsten Schritt im Detail zu untersuchen, ob der von mir pauschal skizzierte Sachverhalt nicht noch stärker regionalisiert werden muß, d.h. ob man den ,Westen' und den ,Osten' überhaupt als Einheiten betrachten kann, und dabei wird sich zweifellos noch weiterer Differenzierungsbedarf ergeben, wodurch aber mein grundsätzliches Ergebnis - soweit ich es momentan überblicke - nicht prinzipiell infrage gestellt wird. Zum anderen wäre zu fragen, ob nicht auch schon vor der Spätantike die Formen eschatologischen Denkens unter den Christen so unterschiedlich waren, daß es vielleicht angebracht wäre, in diesem Bereich generell mit größerer Vorsicht zu operieren - in diesem Fall wäre mein Ergebnis für das 6. Jahrhundert immerhin nicht mehr ganz so ernüchternd. Einen noch grundsätzlicheren Punkt berührt schließlich die letzte Frage, die zu stellen wäre: Besaß das antike Christentum überhaupt aus sich selbst heraus ein gesteigertes Potential gesellschaftlicher Integrationsfähigkeit, oder konnte es dieses nur dann entwickeln, wenn ein äußerer Gegner, von dem man sich absetzen konnte, vorhanden war, wie bis zum 4./5. Jahrhundert die ,Heiden' (die - wie HarTmuT LEPPIN jüngst noch einmal gezeigt hat - als Gruppe ja ein christliches Konstrukt darstellen ${ }^{120}$ ) oder seit dem 2. Viertel des 7. Jahrhunderts der Islam, der es ja erst ermöglicht hat, Byzanz als das, christliche Reich des Orients' zu konzeptionalisieren. Jedenfalls ist auffällig, daß in der kurzen Phase, in der die Dominanz des Christentums im wesentlichen unbestritten war, ein beachtlicher Entfremdungsprozeß zwischen christlichen Gesellschaften zu beobachten ist. ${ }^{121}$

119 Vgl. P. Brown, Östliches und westliches Christentum in der Spätantike: Wie sich die Wege trennten, in: Ders., Die Gesellschaft und das Übernatürliche. Vier Studien zum frühen Christentum. Berlin 1993, 48-65, 99-105, bes. $54 \mathrm{ff}$.

120 Vgl. H. Leppin, Zum Wandel des spätantiken Heidentums, Millennium 1 (2004) 5981.

121 An dieser Stelle ließe sich einwenden, daß ja auch während der Auseinandersetzung mit den Heiden innerchristliche Kontroversen an der Tagesordnung waren, daß die Christen also nie eine kohärente Einheit dargestellt haben. Der entscheidende Unterschied zwischen diesen Auseinandersetzungen und dem hier skizzierten Sachverhalt besteht aber darin, daß solche Konflikte immerhin die Existenz von Kommunikation bezeugen, daß 
Was bedeutet dies nun für die eingangs angesprochene europäische Perspektive?

Es hat sich einmal mehr gezeigt, daß die Entwicklung vom Imperium Romanum zum heutigen vereinten Europa keinesfalls als kontinuierlicher Wachstums- und Verdichtungsprozeß verstanden werden darf, auch wenn das Römische Reich in verschiedener Hinsicht bereits Errungenschaften der europäischen Union zu antizipieren scheint. ${ }^{122}$ Aber gerade darin liegt ein verführerischer Anreiz für Fehlschlüsse. ${ }^{123}$ Das antike Konzept von Europa, das auch zur Zeit der Entfaltung des Imperium Romanum weiterhin gültig war, ist vorwiegend geographisch determiniert und ließ sich nur partiell als Grundlage für bedeutendere Identifikations- und Abgrenzungsprozesse heranziehen (etwa in den Konflikten zwischen Griechen und Persern seit dem frühen 5. Jh. v. Chr.). ${ }^{124}$ Erst im Zuge der Umwälzungen in der Spätantike und vor allem ihrer Folgen entstand eine Vorstellung von Europa, und zwar als einer spezifischen Leidensgemeinschaft, die sich auch geographisch bestimmte, die aber vor allem aus den gemeinsamen Erfahrungen unter der Völkerwanderung ihr spezifisches Identifikationspotential gewann. In diesem Prozeß scheint mir das 6. Jahrhundert einen wichtigen Markstein darzustellen. ${ }^{125}$ So konnte etwa Gregor d. Gr. gegenüber dem oströmischen Kaiser Maurikios darüber klagen, daß sich Europa in den Händen der Barbaren befinde - und er meinte dies im Gegensatz

diese möglicherweise durch die zahllosen Divergenzen sogar noch intensiviert worden ist. Der Befund im Hinblick auf eschatologische Fragen zeigt aber, daß in diesem Bereich im 6. Jh. überhaupt keine Kommunikation mehr stattfand, d. h. es wurde nicht einmal mehr gestritten.

122 Vgl. G. Alföldy, Das Imperium Romanum - ein Vorbild für das vereinte Europa? Basel 1999.

123 Vgl. K. M. Girardet, Bundesstaaten im antiken Griechenland und das römische Imperium als ,supranationale' Ordnung - Modelle für ein vereintes Europa von morgen?, in: R. Marti (Hg.), Europa. Traditionen - Werte - Perspektiven. St. Ingbert 2000, 13-48, bes. $29 \mathrm{ff}$.

124 Vgl. M. Fuhrmann, Alexander von Roes: Ein Wegbereiter des Europagedankens? (Sb. der Heidelberger AdW, Jg. 1994, H. 4). Heidelberg 1994, 8 ff.; J. Cobet, Europa und Asien - Griechen und Barbaren - Osten und Westen. Zur Begründung Europas aus der Antike, Geschichte in Wissenschaft und Unterricht 47 (1996) 405-419; A. Demandt, Europa: Begriff und Gedanke in der Antike, in: P. Kneissl/V. Losemann (Hgg.), Imperium Romanum. Studien zu Geschichte und Rezeption. Festschrift für Karl Christ zum 75. Geburtstag. Stuttgart 1998, 137-157, bes. 141 ff.; J. A. Schlumberger, Europas antikes Erbe, in: J. A. Schlumberger/P. Segl (Hgg.), Europa - aber was ist es? Aspekte seiner Identität in interdisziplinärer Sicht. Köln/Weimar/Wien 1994, 1-19, hier 6 ff., ist sogar im Hinblick auf die Perserkriege skeptisch.

125 J. Fischer, Oriens - Occidens - Europa. Begriff und Gedanke „Europa“ in der späten Antike und im frühen Mittelalter. Wiesbaden 1957, 39 ff., bes. 43, der diesen Prozeß allerdings schon in der Zeit um 400 einsetzen sieht; ähnlich Fuhrmann, Alexander von Roes (wie Anm. 124), 18 ff.; korrigierend Schlumberger, Europas antikes Erbe (wie Anm. 124), $11 \mathrm{f}$. 
zum Gebiet Ostroms, das weitgehend intakt geblieben schien (und sich der Jurisdiktion des Papstes entzog). ${ }^{126}$ Damals verloren westliche Betrachter den Osten des ehemaligen Reiches, der die Wirren überstand und nicht in ein Konglomerat gentiler Reichsbildungen aufging, allmählich aus den Augen. Vor allem im 6. Jahrhundert ging Byzanz den sich allmählich formierenden ,Europäern' verloren, begab sich auf eigene Wege und vollzog dabei eine auch ganz eigene Entwicklung.

126 Greg. epist. 5,37 (ed. Norberg [wie Anm. 59], 309,53): ecce cuncta in Europae partibus barbarorum iuri sunt tradita; dazu Simonetti, Gregorio Magno (wie Anm. 55), $326 \mathrm{f}$. 
